\title{
Víctima, reparación y proceso penal: una proyección desde las teorías expresivas de la pena
}

\author{
Victim, reparation and criminal process: a projection \\ from the expressive theories of punishment
}

Vítima, reparação e processo criminal: uma projeção das teorias expressivas da pena

\section{Ramón Beltrán Calfurrapa ${ }^{1}$}

Universidad de Atacama - Chile rambel@gmail.com

http://orcid.org/0000-0002-6028-9534

ResUMEN: El presente artículo pretende examinar los aspectos más relevantes de la reparación por el hecho punible, en favor de la víctima, bajo el supuesto de las denominadas "teorías expresivas de la pena". Para ello, luego de exponer sucintamente la importancia y relevancia de la reparación en el ámbito penal y procesal penal, abordará su imbricación político-criminal a partir de los paradigmas y postulados esenciales sustentados por dichas teorías. En particular, analizará si la reparación penal puede o no ser entendida bajo un "telos" expresivo y, de ser así, si su dimensión fáctica y comunicativa puede restablecer el déficit normativo generado por el delito.

Palabras-Clave: víctimas; reparación; proceso penal; teorías expresivas de la pena.

ABSTRACT: The present article tries to examine the most relevant aspects of the reparation of crime, in favor of the victim, under the assumption of the socalled "expressive theories of punishment". For this, after explaining succinctly

1 Doctor en Derecho por la Pontificia Universidad Católica de Valparaíso, Chile. Profesor de Derecho Procesal e Introduccióan al Derecho en la Facultad de Ciencias Jurídicas y Sociales de la Universidad de Atacama, Copiapó, Chile. Miembro de la Red Chilena de Investigadores de Derecho Procesal. Abogado. 
the importance and relevancy of the reparation in the field of criminal law and criminal procedure, will treat its political-criminal linkage based on the paradigms and essential postulates supported by such theories. In particular, it will analyze whether criminal reparation may or may not be understood under an expressive "telos" and, if so, whether its factual and communicative dimension can restore the normative deficit generated by the crime.

KEYWORDS: victims; reparation; criminal procedure; expressive theories of punishment.

RESUMO: O presente artigo procura examinar os aspectos mais relevantes da reparação pelo crime, em favor da vítima, sob o pressuposto das chamadas "teorias expressivas da pena". Para isso, depois de explicar sucintamente a importância e a relevância da reparação no campo do direito penal e do processo penal, tratará sua vinculação político-criminal a partir dos paradigmas e postulados essenciais apoiados por essas teorias. Em particular, analisará se a reparação criminal pode ou não ser entendida sob um "telos" expressivo e, em caso positivo, se a sua dimensão factual e comunicativa pode restaurar o déficit normativo gerado pelo crime.

Palavras-Chave: vítimas; reparação; processo penal; teorias expressivas da pena.

SUMARIO: Introducción y planteamiento; 1 . La reparación en el ámbito penal y procesal penal; 2. Las teorías expresivas de la pena y sus aspectos más relevantes; 3 . La reparación a la luz de las teorías expresivas de la pena; Consideraciones finales; Referencias bibliográficas.

"La pena provoca una herida, el resarcimiento del daño cura otra, en lo posible, sin causar una segunda”. Karl Binding, Die Normen und ihre Übertraetung, t. I, §41, p. 288.

\section{INTRODUCCIÓN Y PLANTEAMIENTO}

"En un Derecho penal entre hombres libres e iguales, la reparación debería ser la sanción principal, y la solución de la controversia por 
composición y por resarcimiento del daño, el procedimiento preferido"2. Con estas palabras WeIgend, citando a MAIHOFER, llamaba la atención de la comunidad académica alemana el año 1981, sintetizando, enfáticamente, la necesidad de dar cabida a la reparación como una tercera vía de solución al conflicto penal. Por supuesto, desde dicha época hasta la fecha, tal enfoque se ha ido asentando progresivamente al punto de constituir un fenómeno con una estructura e identidad propia, merced los diversos aportes efectuados por el modelo de "justicia restaurativa" sugerido por corrientes de pensamiento propias de países anglosajones ${ }^{3}$.

Sin embargo, se trata de una cuestión político-criminal de hondas raíces, tanto con partidarios como detractores, que, por lo demás, refleja la constante crisis y tensión que se vive dentro de la cuestión penal. En efecto, inspirada en una vocación clásica de tipo unilateral y vertical, la ciencia penal durante mucho tiempo focalizó sus esfuerzos en torno a la persona del autor y el restablecimiento de las relaciones normativas resquebrajadas por la comisión del delito. El enjuiciamiento, la condena y la pena, desde esta óptica, expresaban exclusivamente la desaprobación y el reproche público de la conducta delictuosa, razón por la cual, con

2 "In einem Strafrecht zwischen Freien und Gleichen müsse demgegenüber Wiedergutmachung die primäre Sanktion, Streiterledigung durch Sühnevertrag und Ausgleich des Schadens das bevorzugte Verfahren sein”. WEIGEND, Thomas. Tagungsbericht (Diskussionsbeiträge der Strafrechtslehrertagung 1981 in Bielefeld). Zeitschrift für die gesamte Strafrechtswissenschaft [ZstW], $\mathrm{n}^{\circ} 93$, 1981, pp. 1283-1284.

3 Sobre los modelos de justicia restaurativa anglosajones, su evolución y elementos más sobresalientes, véanse, entre otros: VAN NESS, Daniel W; HEETDERKS STRONG, Karen. Restoring justice: an introduction to restorative justice. 5ta edición. Ámsterdam- Boston- Heidelberg- London: Anderson Publishing, 2015, pp. 23 ss; TAMARIT SUMALLA, Josep M. Procesos restaurativos más allá de la mediación: perspectivas de futuro. En: AA.VV. Justicia restaurativa, una justicia para el siglo XXI: potencialidades y retos. Bilbao: Publicaciones Universidad de Deusto, 2013, pp. 317-328; LUNA, Erik. In Support of restorative justice. En: ROBINSON, Paul; GARVEY, Stephen; KESSLER, Kimberly (editores). Criminal law conversations. Oxford: Oxford University Press, 2009, pp. 585 ss. MANNOZZI, Grazia. La giustizia senza spada. Uno studio comparato su giustizia riparativa e mediazione penale. Milano: Giuffré, 2003, pp. 125 ss; WRIGHT, Martin. Justice for victims and offenders a restorative response to crime. 2da edición. Winchester: Waterside Press, 1996, pp. 11 ss; CRAGG, Wesley. The practice of punishment: towards a theory of restorative justice. Londres- New York: Routledge, 1992, pp. 138 ss. 
el fin de hacer posible un ideal de justicia imparcial e independiente ${ }^{4}$, se procuró distanciar y alejar a la víctima lo más posible del escenario procesal penal. El ofendido por el delito y sus derechos, por tanto, eran vistos como una cuestión marginal, fungible y residual no susceptibles de consideración directa en el enjuiciamiento criminal ${ }^{5}$.

Con todo, y pese al trasfondo liberal y garantista que se trataba de asegurar, bien pronto se observó que una redefinición del rol de la víctima en el campo procesal penal no implicaba, necesariamente, un retorno involutivo a las etapas primitivas propias de la justicia penal privada. Antes bien, se observó que el delito genera una relación plurilateral que vincula al autor, la víctima y la sociedad, y que, además del plano vertical propio de la imposición de una pena o una medida de seguridad, puede existir una pacificación social del conflicto desde un plano interpersonal y horizontal ${ }^{6}$. A partir de allí, haciendo eco del carácter subsidiario, fragmentario y de "ultima ratio" del sistema penal, se han tratado de desarrollar diversos criterios procesales de reparación material o simbólica, dando paso paulatino a la injerencia de la composición, el consenso y la autonomía de la voluntad como herramientas claves para buscar una alternativa de solución al conflicto punitivo.

Pero sería un error suponer que el actual repunte de la víctima y sus derechos en el ámbito procesal penal está ausente de riesgos. De

4 Cfr. COEN, Rebecca. The Rise of the victim- A Path to punitiveness? Irish Criminal Law Journal, $\mathrm{n}^{\circ} 16,2006$, pp. 10 ss.

5 Sobre la víctima como figura marginal del proceso y su "resurgimiento", Cfr. VENTUROLI, Marco. La vittima nel sistema penale dall'oblio al protagonismo?. Napoli: Jovene editore, 2015, pp. 7 ss; GÓMEZ COLOMER, José Luis. Estatuto jurídico de la víctima del delito. (La posición jurídica de la víctima del delito ante la justicia penal. Un análisis basado en el Derecho comparado y en las grandes reformas españolas que se avecinan). Pamplona: Thomson Reuters Aranzadi, 2014, pp. 35 ss; CORNACCHIA, Luigi. Vittime e giustizia criminale. Rivista Italiana di Diritto e Procedura Penale, fasc. 4. Milano: Giuffrè, 2013, pp. 1760 ss; ESER, Albin. Acerca del renacimiento de la víctima en el procedimiento penal. Tendencias nacionales e internacionales. En: AA.VV. De los delitos y las víctimas. Buenos Aires: Ad-Hoc, 1992, pp. 16 ss.

6 Para un análisis más detallado sobre el carácter vertical y horizontal del delito y la correspondiente respuesta sancionatoria, Cfr. SILVA SANCHÉZ, Jesús-María. Malum Passionis. Mitigar el dolor del Derecho penal. Barcelona: Atelier, 2018, pp. 21 ss. 
hecho, subsiste aún el justo temor -a lo menos en el ámbito estrictamente científico- de que la imagen de la "víctima real o potencial" sea mal utilizada, esto es, sea mediatizada por eslóganes subjetivos, pasionales y populistas, encarnados, por lo demás, a través de un Derecho penal simbólico. Piénsese, en este sentido, en los planteamientos propios de la actual "seguridad ciudadana", la política de la "tolerancia cero" o los continuos reparos surgidos a partir del "nothing works", los cuales, bajo el eslogan de salvaguardar a las víctimas, han propiciado la institucionalización de una auténtica justicia represiva y autoritaria. Se teme pues que la participación de las víctimas, particularmente en la determinación del "si” y el "cuánto" de la pena, pueda erosionar y lesionar principios garantísticos tan básicos como los de culpabilidad, proporcionalidad e igualdad ${ }^{8}$. De ahí que resulte imprescindible, por tanto, determinar cuál es la política-criminal que está detrás de los equivalentes funcionales que se esbozan como manifestativos de la reparación y, de este modo, se puedan analizar críticamente los postulados y directrices sobre los cuales se sustentan.

Por consiguiente, y a objeto de delimitar nuestro objeto de estudio, en las próximas páginas abordaremos los aspectos más relevantes de la reparación del daño causado a la víctima, bajo los supuestos sustentados por las denominadas "teorías expresivas de la pena". Para ello, luego de analizar sucintamente la importancia y relevancia de la reparación del daño en el ámbito penal y procesal penal, así como los aspectos dogmáticos más destacados de dichas teorías de la pena, trataremos de responder a preguntas tales como: ¿Puede producir la reparación real o simbólica efectos expresivos o comunicativos? ¿Bastará acaso un acuerdo conciliatorio entre víctima y ofensor para alcanzar tales fines? ¿puede la reparación implicar un "mal" capaz de restablecer el déficit comunicativo generado

7 Sobre la diferenciación entre víctima actual y potencial, Cfr. SEELMANN, Kurt. Paradojas de la orientación hacia la víctima en el Derecho penal. En: SEELMANN, Kurt. Estudios de filosofía del Derecho y Derecho penal. Trad. Raúl Núñez Ojeda y Thomas Vogt Geisse. Madrid, Barcelona, Buenos Aires, São Paulo: Marcial Pons, 2013, pp. 189 ss.

8 Sobre la víctima como medio de debilitamiento de los principios del Estado constitucional, Cfr. ALBRECHT, Peter-Alexis, La funcionalización de la víctima en el sistema de justicia penal. En: AA.VV. La víctima en el sistema penal. Dogmática, proceso y política criminal. Trad. Luis Reyna Alfaro. Lima, Grijley, 2006, pp. 58 ss. 
por el delito? Así las cosas, asumiendo que toda respuesta punitiva entraña tanto una dimensión fáctica cuanto comunicativa, concluiremos que sí es posible irrogar tales efectos expresivos a la reparación penal y, por tanto, entenderla como un equivalente funcional a la pena bajo ciertas condiciones y presupuestos que se abordaran al final de este trabajo.

\section{1.- La RePARACión EN el Ámbito PenAl y PROCESAL PENAL}

Constituye prácticamente un lugar común la afirmación de que el daño que experimenta la víctima por el delito no se agota, necesariamente, con la lesión o puesta en peligro de los bienes jurídicos protegidos por las normas penales. Antes bien, aquél se extiende y proyecta también en una dimensión inmaterial y personal, muchas veces imperceptible, pero duradera, que desencadena a menudo padecimientos progresivos para el ofendido por el delito. Desde luego, la naturaleza del ilícito penal, la energía criminal desplegada por el delincuente en su comisión, así como la mayor o menor sensibilidad de la víctima al delito, influyen de sobremanera en que tales secuelas se amplifiquen con el correr del tiempo ${ }^{9}$. Al abatimiento, la angustia y el justo temor de ser presa nuevamente de un ilícito, se añaden, por tanto, otros efectos colaterales y accesorios propios de la victimización secundaria ${ }^{10}$ : por un lado, la ira, la animosidad y el resentimiento frente a la humillación causada por el delito; y, por otro, la necesidad de compensación y restablecimiento al "status quo" anterior al hecho punible.

La aplicación de la pena, naturalmente, coadyuva a paliar en algo las anteriores nocividades. Sin embargo, sería ingenuo creer que la aflicción de la privación de libertad y sus efectos reparan "per se" los daños materiales e inmateriales causados por el delito. En efecto, si bien se debe

9 Para un análisis de tales factores a la luz de la medición judicial de la pena, Cfr. HÖRNLE, Tatjana. Distribution of punishment: the role of a victim's perspective. Buffalo Criminal Law Review, vol. 3, nº 1, pp. 188 ss, 1999.

10 Vinculando la victimización secundaria únicamente al impacto que sufre la víctima al entrar en contacto con las instancias estatales de justicia, Cfr. WEMMERS, Jo-Anne. Victims' experiences in the criminal justice system and their recovery from crime. International Review of Victimology, vol 19, n ${ }^{\circ}$ 3, pp. 221 ss, 2013. 
tener precaución al hacer suposiciones sobre lo que las víctimas realmente buscan a través de su participación en el proceso penal ${ }^{11}$, diversos estudios han sugerido que las víctimas no parecen ser más punitivas que la opinión pública en relación con la represión propia del sistema ${ }^{12}$. Antes bien, lejos de buscar la punición desmedida y a toda costa, la mayoría de los ofendidos por el delito al parecer tienden a priorizar el reconocimiento, la compensación y el restablecimiento por sobre la punición ${ }^{13}$. De este modo, quizás movidos por intereses materiales o terapéuticos, pero también por mayores expectativas de participación, apoyo y consideración, las actitudes más pasionales de las víctimas cederían en pos de actitudes más reflexivas de perdón, clemencia y reparación ${ }^{14}$. De ahí que un adecuado sistema de reacción al delito deba considerar, además del concreto grado

11 Es de sobra conocido, en este sentido, que el tratamiento simbólico dado por los «mass media» al delito ha contribuido a generar mitos distorsionados y mediáticos sobre los que se sustenta el actual discurso punitivo. Sin embargo, como bien sostiene Varona, "no se trata de un discurso permeable a todo estímulo. Cuando esas imágenes culturales construidas mediáticamente son confrontadas con datos y con otro discurso se puede producir un replanteamiento de las mismas. $Y$, por otro lado, no es un discurso uniforme y monolítico: los ciudadanos son capaces de articular argumentos diversos en función del tipo de delincuencia en que están pensando". VARONA GÓMEZ, Daniel, El debate ciudadano sobre la justicia penal y el castigo: razón y emoción en el camino hacia un derecho penal democrático. Madrid- Barcelona- Buenos Aires- São Paulo: Marcial Pons, 2016, pp. 147-148.

12 Cfr. VAN CAMP, Tinneke, Understanding victim participation in restorative practices: Looking for justice for oneself as well as for others. European Journal of Criminology, vol. 14, $\mathrm{n}^{\circ}$ 6, pp. 690 ss, 2016; DOAK, Jonathan; HENHAM; Ralph; MITCHELL, Barry. Victims and the sentencing process: developing participatory rights?. Legal Studies, vol. 29, no 4, p. 655, 2009; EREZ, Edna; TONTODONATO, Pamela, The effect of victim participation in sentencing on sentence outcome. Criminology, vol. 28, n 3, pp. 467 ss, 1990.

13 Quizá por ello, como expresan Wemmers y Cyr, "Given that victims do not seek decision-making power, but simply want to be taken into consideration, victim participation in the criminal justice process should not pose a threat to the existing power balance, nor to the rights of the accused within the conventional criminal justice system". WEMMERS, Jo-anne; CYR, Katie. Victims' perspectives on restorative justice: how much involvement are victims looking for? International Review of Victimology, vol. 3, p. 271, 2004.

${ }_{14}$ Sobre la necesidad de replantearse la importancia del perdón en el proceso penal, Cfr. LACEY, Nicola; PICKARD, Hanna. To blame or to forgive? Reconciling punishment and forgiveness in criminal justice. Oxford Journal of Legal Studies, vol. 35, nº 4, pp. 688 ss, 2015; BIBAS, Stephanos; BIERSCHBACH, 
de satisfacción de la pretensión punitiva del Estado, las justas expectativas y exigencias de reparación del daño causado a la víctima. Puede hablarse, por tanto, de la necesidad de instaurar un sistema punitivo pluridimensional e integrativo que considere, además de los intereses y expectativas de la sociedad y del infractor, las justas demandas de la víctima dirigidas a alcanzar una equilibrada y ponderada "reparación".

Lo anterior, en todo caso, no debe entenderse como un intento de sustitución del sistema procesal clásico en pos de una autocomposición privada del conflicto. De lo que se trata más bien es entender que para el Estado, en mayor o menor medida, no pueden resultar indiferentes las diversas heridas causadas por el delito: en primer lugar, a la propia víctima, quien -como vimos- sufre en carne propia no sólo el daño y la estigmatización resultante del delito, sino que también muchas veces la indiferencia y apatía propia del sistema; en segundo lugar, a la sociedad, quien además de ser trastocada en su identidad normativa y comunicativa, se ve afectada por las consecuencias psico-sociales de impotencia, resentimiento e inseguridad que derivan precisamente del injusto-culpable; y, por fin, al propio infractor, que además de experimentar el justo temor de verse expuesto a una sanción de tipo aflictiva, sufre además el aislamiento, el remordimiento e, incluso, la vergüenza por su conducta previa y defectuosa ${ }^{15}$. De ahí que un adecuado sistema de reacción al delito deba mitigar no sólo los inevitables antagonismos que surgen a partir de las anteriores nocividades, sino que también deba intentar conciliar y armonizar "la reparación" como un complemento al enjuiciamiento penal clásico. No se trata, por ende, de buscar una sustitución del sistema procesal penal o, en ciertos casos, de buscar métodos procesales que tiendan a favorecer la penalización de la pretensión resarcitoria. Por el contrario, lo que se pretende es asumir que el Derecho procesal constituye un Derecho de alternativas, que discurre por la vía de la complementariedad y

Richard A. Integrating remorse and apology into criminal procedure. The Yale Law Journal, vol. 114, no 84, pp. 87 ss, 2004.

15 Para un análisis de las emociones de remordimiento, vergüenza y culpa como pasos críticos en el proceso de rehabilitación, Cfr. TANGNEY, June P; STUEWIG, Jef; HAFEZ, Logaina. Shame, guilt, and remorse: implications for offender populations. The Journal of Forensic Psychiatry \& Psychology, vol. 22, $\mathrm{n}^{\circ}$ 5, pp. 706-723, 2011. 
la subsidiariedad en aras de contribuir precisamente a la realización de los fines propios del Derecho Penal. De este modo, allí donde la pacificación social pueda ser alcanzada por medio de sanciones menos graves, el reconocimiento de la reparación como una alternativa justa y viable para las víctimas, la sociedad y el infractor, debería ser siempre propendida, fortalecida y garantizada por parte del Estado ${ }^{16}$.

Pero ¿qué se debe entender por reparación? ¿cuáles son sus proyecciones en el campo penal y procesal penal? ¿Puede acaso ser homologada al simple resarcimiento de perjuicios? Pues bien, antes de responder a estas interrogantes, debe observarse que debido a la influencia de ciertos modelos teóricos, provenientes tanto del "common law" como del "civil law", la reparación no ha sido abordada conceptualmente hablando en un sentido unívoco ${ }^{17}$. En efecto, resurgida históricamente como una reacción

16 En este sentido, cabe afirmar que la relevancia jurídico-penal de la reparación del daño y el efecto pacificador que generaría ha sido abordado por una serie de instrumentos internacionales. Destacan, en este sentido, la Resolución 40/34 de la Asamblea General de las Naciones Unidas, de 29 de noviembre de 1985, sobre "Los Principios Fundamentales de Justicia Para las Víctimas de Delitos y del Abuso de Poder", emitida tras el VII Congreso sobre Prevención del Delito y Tratamiento del Delincuente, celebrado en Milán, Italia, del 26 agosto al 6 de septiembre de 1985; la Resolución 60/147 de la Asamblea General de las Naciones Unidas, de 16 de diciembre de 2005, que fija "Los Principios y Directrices Básicos Sobre el Derecho de las Víctimas de Violaciones Graves del Derecho Internacional Humanitario a Interponer Recursos y Obtener Reparaciones"; y, además, la Directiva 2012/29/UE del Parlamento Europeo y del Consejo, de 25 de octubre de 2012, por la que Se Establecen Normas Mínimas Sobre los Derechos, el Apoyo y la Protección de las Víctimas de Delitos, y por la que se Sustituye la Decisión Marco 2001/220/JAI del Consejo. En nuestro ámbito interamericano, por el contrario, a pesar que no existen declaraciones emitidas en términos similares, sí se evidencian una serie de pronunciamientos sostenidos por la Corte Interamericana de Derechos Humanos, en los cuales, a partir del artículo 63 de la Convención Americana de 1969, ha decantado el concepto de "reparación integral" como garantía básica para las víctimas en materia de derechos humanos. Para un análisis de tales pronunciamientos, Cfr. NASH ROJAS, Claudio. Las Reparaciones ante la Corte Interamericana de Derechos Humanos (1988-2007). Segunda Edición. Santiago de Chile, Universidad de Chile, 2009, pp. 33 ss.

17 En argumento, Cfr. LARRAURI PIJOÁN, Elena. Justicia restauradora y violencia doméstica. En: ASUA BATARRITA, Adela; GARRO CARRERA, Enara (editoras). Hechos postdelictivos y sistema de individualización de la pena. Bilbao: Servicio Editorial de la Universidad del País Vasco, 2008, pp. 125 ss. 
frente a la crisis de los modelos disuasorios y resocializadores, la actual configuración de la reparación presenta rasgos variados y disímiles, dado el alto influjo ideológico de las diversas corrientes de pensamiento que le han servido de sustento ${ }^{18}$ : en aquélla confluyen, por cierto, rasgos de los sistemas de "diversion" anglosajones, postulados propios de los movimientos abolicionistas, así como también diversas directrices victimológicas surgidas la segunda mitad del siglo XX. Sin embargo, y más allá que probablemente nunca se logre un consenso absoluto sobre sus posibles matices y particularidades, lo cierto es que el "leiv motiv" que le sirve de sustento es casi siempre el mismo: incluir a la reparación dentro del sistema de sanciones penales. De ahí que, superando los dilemas propios del clásico "malum passionis", se haya comprendido que la reparación del daño a la víctima no constituye un cuerpo extraño a lo penal, sino, todo lo contrario $^{19}$ : que en algunos casos puede operar como una atenuante de la pena, en otros puede implicar una condición para decretar la suspensión de la pena e, incluso, para cierto tipo de delitos, puede llegar a constituir un auténtico sustituto de la pena. Se trata, por tanto, de una "tercera vía" ("dritte Spur") alternativa y complementaria de las penas y las medidas de seguridad, que englobaría un conjunto de conductas que el infractor debiese desplegar en beneficio de la víctima o la sociedad, y que, en tal carácter, se traducen en una serie de prestaciones de contenido material, simbólico o ideal, a objeto de alcanzar precisamente una adecuada pacificación del conflicto social ${ }^{20}$.

18 Refiriéndose a los antecedentes ideológicos de la reparación, Cfr. GARCÍA-PABLOS DE MOLINA, Antonio. Análisis criminológico de los diversos modelos y sistemas de reacción al delito. En: AA.VV. El nuevo Código Penal: presupuestos y fundamentos: (libro homenaje al profesor Doctor Don Angel Torío López). Granada: Comares, 1999, p. 143.

19 Apelando a la reparación como parte esencial de la sanción penal, Cfr. ESER, Albin. Sobre la exaltación del bien jurídico a costa de la víctima. Trad. Manuel Cancio Meliá. Bogotá: Universidad Externado de Colombia, 1998, p. 42.

20 Un concepto de reparación como el sugerido, fue el que elaboró un grupo de profesores alemanes, austriacos y suizos, en el denominado "Proyecto Alternativo sobre la Reparación” (“Alternativ-Entwurf Wiedergutmachung”-AEWGM-), el cual, con un total de 25 parágrafos y 3 apartados, fue presentado el año 1992 en el contexto del quincuagésimo noveno «Deutscher Juristentag», celebrado en la ciudad de Hannover, Alemania. Así, en su § 1, punto 1, sostiene: "Se entiende por reparación la compensación de las consecuencias 
Ahora bien, si la reparación entre víctima y autor ha logrado un reconocimiento tan amplio, ello se debe, en parte, no sólo por las posibles ventajas que supone para las víctimas, el ofensor o la sociedad, sino también porque considera de forma integrativa y contingente las diversas dimensiones del daño. En efecto, a diferencia de lo que sucede con la indemnización de perjuicios civiles y sus conocidos criterios de procedencia, la reparación penal posee una estructura que no se agota en el contenido de esta última. Ello, pues, a pesar que una de sus posibles prestaciones pueda ostentar un contenido pecuniario, la determinación jurídico-penal de su estructura, así como la voluntariedad de su ejecución ${ }^{21}$, hacen que la reparación extienda sus efectos a través de una diversidad de prestaciones: en primer lugar, la restitución, esto es, el restablecimiento -en la medida de lo posible- a la situación originaria en que se encontraba la víctima antes del ilícito; en segundo lugar, la indemnización, vale decir, el pago de los perjuicios materiales y morales que sean consecuencia de delito; en tercer lugar, la satisfacción, esto es, la verificación de una serie de conductas del infractor que pueden ir, desde disculpas públicas que restablezcan la honra, la dignidad y los derechos de la víctima, hasta la realización de obras, trabajos o faenas que vayan en beneficio del ofendido o de la sociedad; y, por último, las garantías de no repetición, es decir, la adopción de una serie de medidas de tratamiento y de prevención, según proceda, con el objeto de que la conducta criminosa y sus efectos lesivos se mitiguen y no se vuelvan a $\operatorname{reiterar}^{22}$. De ahí que asumiendo que la

del hecho delictivo a través de una prestación voluntaria del autor. Su objetivo es servir al restablecimiento de la paz jurídica. La reparación deberá realizarse preferentemente a favor del ofendido; si ello no fuera posible, no pudiera preverse un buen resultado o por sí sola no fuera suficiente, cabría admitir una reparación a favor de la generalidad (reparación simbólica)". Sobre la génesis del "Proyecto Alternativo sobre Reparación”, sus antecedentes y documentos previos, así como la discusión posterior generada en Alemania, Cfr. PÉREZ SANZBERRO, Guadalupe. Reparación y conciliación en el sistema penal ¿Apertura de una nueva vía?. Granada: Comares, 1999, pp. 268 ss.

21 Cfr. HUBER, Bárbara. Sanciones intermedias entre la pena de multa y la pena privativa de libertad (Sobre la discusión en tomo a las penas ambulatorias y de contenido comunitario). Anuario de Derecho Penal y Ciencias Penales, vol. XLVII (1994), p. 170.

22 Apelando a un orden de prelación de las prestaciones reparadoras: desde el restablecimiento, pasando por la indemnización, hasta llegar a otras formas 
actividad humana es vasta, variada y contingente, pero que se encuentra delimitada también por deberes de cuidado relativamente bien definidos, una cabal compresión de la reparación deba focalizarse no sólo en los daños materiales e inmateriales que sufre la víctima, sino que también en los daños ideales o simbólicos que experimenta la sociedad como consecuencia del delito ${ }^{23}$. La reparación penal, por tanto, ofrecería así una suerte de "plasticidad contingente" frente a los efectos lesivos de la conducta criminal, superando, por ende, la sola visión iusprivatista o residual que algunos autores han intentado irrogarle ${ }^{24}$.

Naturalmente, existen hechos punibles que no son susceptibles de reparación (como los homicidios o los crímenes violentos), así como también hay delitos en los cuales no existe una víctima concreta (como los llamados "victimless crimes") ${ }^{25}$, pero incluso en estos casos la reparación igualmente logra operar: en los primeros, como una posible atenuante al tiempo de determinar el "quantum" de la pena; en los segundos, a través de prestaciones reparadoras en beneficio de la comunidad que, simbólicamente hablando, suponen un restablecimiento de la norma quebrantada por el delito. Estamos aquí, sin embargo, ante situaciones paradigmáticas donde si bien convergen intereses disimiles, no deberían, por exceso o por defecto, ser objeto de una distorsión interpretativa, esto es: que la virtualidad de la reparación no depende tanto de la ejecución y materialidad de la prestación, sino del acto personal y del esfuerzo serio

de reparación simbólica, Cfr. ALASTUEY DOBÓN, M. Carmen. La reparación a la víctima en el marco de las sanciones penales. Valencia: Tirant lo Blanch, 2000, p. 67.

23 Sobre la vinculación entre el delito y el daño, Cfr. SILVA SÁNCHEZ, Jesús-María. En Busca del Derecho Penal. Esbozos de una teoría realista del delito $y$ de la pena. Montevideo- Buenos Aires: B de F, 2015, pp. 157-159.

24 Así, Cfr. MUÑOZ CONDE, Francisco; GARCÍA ARÁN, Mercedes. Derecho penal: parte general. 6ta edición. Valencia: Tirant lo Blanch, 2004, pp. 605 ss; FERRAJOLI, Luigi. Derecho y razón: teoría del garantismo penal. 6ta edición. Madrid: Trotta, 2004, p. 420; HIRSCH, Hans Joachim. La reparación del daño en el marco del Derecho penal material. En: AA.VV. De los delitos y de las víctimas. Trad. Elena Carranza. Buenos Aires, Ad-Hoc, 1992, pp. 60 ss.

25 Como sucede, por ejemplo, con el manejo en estado de ebriedad, sin resultados lesivos; o bien, en muchos delitos contra bienes jurídicos supraindividuales, como el falso testimonio, el perjurio, etc. 
de restablecimiento que el autor manifiesta en pos de su concreción ${ }^{26}$. De ahí la importancia del "valor de la acción" como criterio clave para interpretar la reparación, entendida, en todo caso, siempre desde una dimensión fáctico-comunicativa en atención al nivel de nocividad expresado por el injusto ${ }^{27}$. De este modo, por consiguiente, "no se trataría de preguntar al acusado sobre su "voluntad de restaurar la vigencia de la norma", sino de atender al significado comunicativo que deriva de la forma de llevar a cabo la prestación. Y lo que debiera comunicar a tal efecto, es la disponibilidad de rectificar mediante actos que visibilicen el reconocimiento del carácter ilícito de su conducta previa, de manera que pueda operar como una forma de reconocer la necesidad de respetar aquellas normas que previamente despreció" ${ }^{28}$.

Con todo, y sin perjuicio de lo ya dicho, puede estimarse como dominante la postura de quienes reconocen el protagonismo de la reparación tanto en la medición judicial de la pena, en la ejecución de la pena e, incluso, también, en lugar y en remplazo de la pena. En un modelo así concebido, en todo caso, fuerza inquirir cuáles son las vías o mecanismos a través de los cuales procesalmente hablando la reparación se puede concretar. Ello, pues, al margen que ésta juegue un rol relevante junto con la pena, también puede constituir una sanción penal autónoma e independiente, diversa, naturalmente, de la pena o de la medida de seguridad.

26 Cfr. ALCÁCER GIRAO, Rafael. La mediación penal y la atenuante de reparación: similitudes y criterios de aplicación. En, AA.VV. Justicia restaurativa, mediación penal y penitenciaria: un renovado impulso. Madrid: Reus, 2011, p. 125.

27 Ello permitiría comprender, por lo demás, que la simple compensación "económica" no cumpliría un fin en sí misma en la reparación. Esto, pues, de mediar una interpretación diversa, bastaría con que una persona con alto potencial económico solvente los daños producidos por el delito y, de este modo, pueda ver eximida o atenuada su responsabilidade penal; o, por el contrario, que una persona en situación económica deficiente no pueda acceder a los beneficios que derivan de la reparación. En suma, debe comprenderse que si bien en la reparación confluyen intereses personales de la víctima y del autor, también se evidencian intereses públicos en aras de mantener precisamente la vigencia de la norma quebrantada por el delito.

28 GARRO CARRERA, Enara. La atenuante de reparación del daño. En: GARRO CARRERA, Enara; ASUA BATARRITA, Adela. Atenuantes de reparación y de confesión: equívocos de la orientación utilitarista. Valencia: Universidad del País Vasco- Tirant lo Blanch, 2008, pp. 59-60. 
Pues bien, para responder a dicha interrogante, se debe asumir que, producto de la redefinición del suceso criminal como un conflicto "sui generis", que vincula al autor, a la víctima y a la sociedad, no desde el paradigma de verticalidad, sino desde el consenso, el acuerdo y la composición, son múltiples los mecanismos a través de las cuales, en nuestro ámbito, la reparación ha encontrado reconocimiento: por un lado, mediante su inclusión dentro del proceso penal clásico a través de la "conciliación”, "los acuerdos reparatorios” y otras formas autocompositivas similares; y, por otro lado, mediante el establecimiento de procedimientos desformalizados, flexibles y operativos que, al margen del proceso penal, facilitarían la composición, la negociación y el acuerdo en pos de la reparación. Naturalmente, en este último caso, existe una sucesión de procedimientos restauradores, combinados, a su vez, con exigencias diferenciadas respecto a la forma de alcanzar cada acuerdo. Sin embargo, la raíz de ellos es casi siempre la misma: promover e impulsar que la víctima y el infractor participen activamente, si dan su consentimiento para ello, en la solución de los problemas resultantes del delito con ayuda de un tercero imparcial.

Ahora bien, quizá de todos los procedimientos existentes en este último sentido, la justicia "restaurativa", también llamada "restauradora", es la que más reconocimiento ha alcanzado el último tiempo. En efecto, con antecedentes remotos en la década de los 80 del siglo pasado, tal paradigma surgió como una respuesta frente a la excesiva burocratización y rigidez del sistema penal clásico, el cual, además de fundarse en un sistema esencialmente contradictorio, represivo y poco participativo, no reconocía a la víctima como un actor relevante en la solución del conflicto penal. Así, asumiendo un cariz más dialogante, flexible, pero por sobretodo más conciliador, la justicia restaurativa alcanzó bien pronto un reconocimiento tal, que diversos organismos internacionales se han encargado de impulsarla como un legítimo mecanismo de solución de conflictos. En ese sentido, destaca la Resolución 2002/12 del Consejo Económico y Social de las Naciones Unidas, la cual, reconociendo los "principios básicos para la aplicación de programas de justicia restitutiva en materia penal”, entendió por proceso restaurativo "todo proceso en que la víctima, el delincuente $y$, cuando proceda, cualesquiera otras personas o miembros de la comunidad afectados por un delito, participen conjuntamente de forma 
activa en la resolución de cuestiones derivadas del delito, por lo general con la ayuda de un facilitador". De ahí que dentro de los procesos restaurativos puedan incluirse a la mediación, la conciliación, la celebración de conversaciones e, incluso, también, las reuniones para decidir condena, como instancias aptas e idóneas para lograr un adecuado resultado restaurador. De este modo, a pesar que sus elementos pueden variar ampliamente, dependiendo de los principios y filosofías en los que se sustentan los sistemas nacionales en cuyo seno se aplican, la filosofía y los principios básicos de los procesos restaurativos son casi siempre los mismos: valores de participación democrática, deliberación, consenso y acuerdo en pos de una adecuada y justa reparación del daño causado por el delito.

\section{LAS TEORÍAS EXPRESIVAS DE LA PENA Y SUS ASPECTOS MÁS RELEVANTES}

Como Feinberg lo señaló en 1965: "tanto las sanciones como las penas son privaciones autoritativas para fracasos; pero aparte de esta característica común, las sanciones tienen un carácter misceláneo, mientras que las penas tienen una característica adicional importante. Esa característica, o diferencia específica, es una cierta función expresiva: La pena es un dispositivo convencional para la expresión de actitudes de resentimiento o indignación, y de juicios de desaprobación y reprobación, ya sea por parte de la autoridad que castiga o de aquellos "en cuyo nombre" se inflige el castigo. La pena, en suma, tiene un significado simbólico que falta en gran medida en otro tipo de sanciones" ${ }^{29}$.

Con estas palabras, y siguiendo de forma crítica los pasos de FLEW30, BENn31 y HART ${ }^{32}$, FeINBERg contribuyó a asentar la idea de

29 FEINBERG, Joel. The expressive function of punishment. The Monist, vol. 49, $\mathrm{n}^{\mathrm{o}}$ 3, p. 400, 1965.

30 Cfr. FLEW, Antony. The justification of punishment. Philosophy, vol. 29, pp. 291-307, 1954.

31 Cfr. BENN, S.I.; PETER, R.S. Social Principles and the democratic state. London: Allen y Unwin, 1959, pp. 174 ss.

32 Cfr. HART, H.L.A. Punishment and responsibility: essays in the philosophy of law. 2da edición. Oxford: Oxford University Press, 2008, pp. 4 ss. 
que la pena comprende dos elementos que deben ser claramente diferenciados: por un lado, la reprobación o reproche simbólico que se realiza al autor por el delito cometido ("reprobative symbolism"); y, por otro, la causación de un mal u otra circunstancia considerada normalmente como no placentera, a objeto de poner al destinatario precisamente en una circunstancia desagradable ("hard treatment"). A partir de allí, se abrió la brecha para que diversos autores, tanto anglosajones como europeo-continentales, desarrollen una serie de criterios en pos de reflejar el carácter expresivo, simbólico o comunicativo de la pena. Tres son, sin embargo, las prevenciones que se deben hacer al respecto. En primer lugar, que las teorías expresivas pretenden proporcionar una justificación de la pena como alternativa a las teorías utilitaristas y retribucionistas tradicionales. Sin embargo, tales teorías se encuentran actualmente en un estado incipiente y preliminar, existiendo además en muchas y diferentes versiones, razón por la cual sería improbable en este punto entenderlas o evaluarlas por completo. En segundo lugar, que tales teorías en estricto rigor no son ni "neo-retribucionistas" ni "neo-proporcionalistas", pues, si por tal prefijo se entiende algo "nuevo" o "reactualizado", las teorías expresivas presentan notables diferencias de lo que serían las posturas retributivas clásicas o tradicionales. De hecho, no es objetivo de las teorías expresivas hacer una suerte de "re-bienvenida" de Kant y HegeL ${ }^{33}$, sino asumir que toda pena, independientemente del fin que se le pretenda irrogar, entraña una dimensión tanto fáctica cuanto comunicativa. Y, en tercer lugar, que la mayoría de las teorías expresivas de la pena no ostentan una estructura "deontológica” sino más bien "consecuencialista” ${ }^{34}$. Ello, pues, al contrario de lo que comúnmente se cree, el utilitarismo no es la única versión del consecuencialismo, ni mucho menos su versión más plausible $^{35}$. De hecho, sería perfectamente razonable asumir una tesis de

33 Esto considerando la despedida de Kant y Hegel que, metafóricamente hablando, Klug planteara en su trabajo titulado precisamente "Abschied von Kant und Hegel”. En: BAUMANN, Jürgen (compilador), Programm für ein neues Strafgesetzbuch. Frankfurt am Main: Fischer, 1968, pp. 36 ss.

34 Intentando dar una justificación “deóntica” de las teorías expresivas, Cfr. PÉREZ BARBERÁ, Gabriel. Problemas y perspectivas de las teorías expresivas de la pena. InDret, $\mathrm{n}^{\circ} 4,2014$, pp. 10 ss.

35 Así, como bien señala Boonin: "Consequentialism is the view that what is morally right is determined entirely by what best promotes the good. And there are 
fundamentación preventiva, retributiva o mixta de la pena y, no obstante ello, seguir acudiendo al consecuencialismo como un espacio meta-ético común para argüir su justificación. De este modo, aunque no se asuma expresamente, la mayoría de las teorías expresivas de la pena presentan una estructura cercana a un "consecuencialismo retribucionista" ${ }^{36}$, sin que con ello, en todo caso, se caiga en una suerte de oxímoron irreductible respecto de los fines y sentidos de la pena ${ }^{37}$.

Ahora bien, sentado lo anterior, conviene precisar que las teorías expresivas de la pena parten de la base, al igual que las teorías preventivas, que la imposición de la pena se funda siempre en los intereses legítimos de las personas. Sin embargo, en su caso particular, el énfasis no va dirigido en pos de incidir en la frecuencia de los delitos futuros, sino en los intereses referidos al tratamiento adecuado del comportamiento pasado. A partir de allí, dos son las ramificaciones en las cuales se tienden a manifestar: por un lado, aquellas que postulan que el mensaje de reprobación punitivo comunica simbólicamente la vigencia de la norma

many other views of the good besides utility, and perhaps many more plausible views as well. A consequentialist might, for example, aim to maximize social stability, or social equality, or the extent to which people get what they deserve, or she might offer a pluralistic conception of the good, consisting of a combination of these and other particular goods, weighted or prioritized in one of a number of possible ways. And so, it might be thought, an argument against the utilitarian solution to the problem of punishment could only count, at most, as one very small part of a much larger argument against the consequentialist solution". BOOMIN, David. The problem of punishment. Cambridge: Cambridge University Press, 2008, p. 80.

Sobre dicha denominación, Cfr. BERMAN, Mitchell. Two kinds of retributivism. En: DUFF, R.A; GREEN, Stuart P (editores). Philosophical foundations of criminal law. Oxford: Oxford University Press, p. 434, 2011. En un mismo sentido, Cfr. MAÑALICH, Juan Pablo. Retribucionismo consecuencialista como programa de ideología punitiva. InDret, $\mathrm{n}^{0} 5$, 2015, pp. 1 ss.

37 Huelga destacar, en todo caso, que autores como Duff y Garland prefieren calificar la "expresividad" como "no consecuencialista", pues, por un lado, ello permitiría fijar la cuantía de la pena en función del merecimiento de la condena moral por el hecho pasado; y, por otro lado, porque así el castigo se impondría como algo intrínsecamente apropiado - no solo contingente y eficaz- como medio para conseguir su objetivo. Sobre esto, Cfr. DUFF, Antony; GARLAND, David. Thinking about Punishment. En: DUFF, Antony; GARLAND, David (editores). A Reader on Punishment. Oxford: Oxford University Press, 1994. pp. 13-14. 
quebrantada por el delito; y, por otro, aquellas que señalan que dicho mensaje de reprobación se dirige a fin de incidir en ciertas personas, tales como el ofensor, la víctima o la sociedad ${ }^{38}$.

\section{A) TEORÍAS EXPRESIVAS ORIENTADAS A LA NORMA}

Una de las variantes de las teorías expresivas asume como tarea de la pena el velar por la vigencia de la norma tras la comisión del delito. Un delito, en efecto, no sólo produce daños que afectan los intereses individuales de los afectados, sino que también ocasiona daños que lesionan diversas "normas jurídicas" que forman parte de nuestra realidad social. De ahí que, frente a la comisión de un hecho punible, tanto el carácter vinculante de la norma, así como su real potencialidad para superar situaciones de crisis, se vean trastocadas y en tela de juicio, produciendo, por ende, una serie de consecuencias cognitivas y psico-sociales indeseadas. La pena, por tanto, ha de reaccionar fácticamente a dichas transgresiones, mostrando principalmente "un significado simbólico de contradicción”, de forma tal de reafirmar su vigencia y "status" y, de este modo, restablecer la paz social y jurídica quebranta por el delito.

Desde esta óptica, y a pesar de su bullado giro "fáctico"39, bien conocidos son los aportes de Јаковs sobre la materia. Según éste, desde planteamientos próximos - al menos inicial o superficialmente-a la teoría de los sistemas de LunmanN ${ }^{40}$, el objetivo que da sentido al Derecho penal

38 Sobre dicha tipología, Cfr. HÖRNLE, Tatjana. Teorías de la pena. Trad. Nuria Pastor. Bogotá: Universidad Externado de Colombia, 2015, pp. 33 ss.

39 Así, SILVA SÁNCHEZ, Jesús-María. Del Derecho abstracto al Derecho Real. Indret, $\mathrm{n}^{\mathrm{o}} 4,2016$, p. 2.

40 Expresada sucintamente, la teoría de los sistemas de Luhmann postula como objetivo primordial la comprensión y explicación de las estructuras sociales, no a partir de su origen histórico y sus peculiaridades temporales, sino más bien a partir de la observación, análisis y estudio de los diversos subsistemas que coexisten de modo autoreferencial y autopoiético dentro de la sociedad. El sistema jurídico, bajo este entendido, sería un subsistema dentro del sistema social, cuya labor principal residiría en la fijación, estabilización y generalización de determinadas expectativas normativas de conducta y, por consiguiente, de determinadas formas previsibles y recursivas de organización suceptibles de ser mantenidas en situaciones conflictuales. 
es la preservación de la sociedad, razón por la cual toda su estructura se erigiría como un sub-sistema de comunicaciones cuya misión sería la estabilización de expectativas normativas por medio de las sanciones ${ }^{41}$. Para JАковS, en efecto, la pena representa un instrumento idóneo para resolver las defraudaciones de expectativas que no pueden ser estabilizadas de otra manera, pues, "si se quiere que la vida en sociedad sea factible, cada uno debería poder dotar de seguridad a sus expectativas, y dado que una seguridad cognitiva sólo sería imaginable en un mundo petrificado al modo de un museo, en la vida social las expectativas deben ser aseguradas normativamente" ${ }^{42}$. Sin embargo, sería un error afirmar que la tesis de JаковS es fruto exclusivo de las ideas de LuHManN plasmadas el campo penal. Ello, pues, lo que se observa en los últimos años, es precisamente todo lo contrario: un distanciamiento del legado del sociólogo de Bielefeld y un acercamiento a postulados propios de la filosofía Hegeliana. De este modo, asumiendo una suerte de lectura "Luhmanniana de Hegel”, la finalidad de la pena, según ЈАков, nо debería estar sustentada en el afán de que el autor del ilícito no vuelva a delinquir, ni mucho menos que nadie delinca, sino únicamente en que se refuerce la vigencia de la norma puesta en tela de juicio precisamente por la comisión del delito.

En cualquier caso, según JAKOBs, la relación entre delito y pena no se encontraría determinada por ningún tipo de relación causal, pero tampoco como consecuencia de una instancia que busque la protección de bienes jurídicos. Dicha relación se establecería más bien desde un plano puramente simbólico, esto es, de significados, donde los comportamientos

Sobre el particular, Cfr. LUHMANN, Niklas. Law as a Social System. Oxford: Oxford University Press, 2004, pp. 53 ss; DURÁN MIGLIARDI, Mario. Introducción a la ciencia jurídico-penal contemporánea. Santiago de Chile: Ediciones Jurídicas de Santiago, 2006, pp. 161 ss; GIMÉNEZ ALCOVER, Pilar, El Derecho en la teoría de la sociedad de Niklas Luhmann. Barcelona: Bosch Editor, 1993, pp. 163 ss.

41 Cfr. JAKOBS, Günther. Derecho penal. Parte general: fundamentos y teoría de la imputación. $2^{\mathrm{a}}$ edición. Trad. Joaquín Cuello Contreras y José Luis Serrano González. Madrid: Marcial Pons, 1997, pp. 10 ss.

42 JAKOBS, Günther. Sobre el tratamiento de los defectos volitivos y de los defectos cognitivos. En: JAKOBS, Günther. Estudios de Derecho penal. Trad. Enrique Peñaranda Ramos y otros. Madrid: Ediciones Universidad Autónoma de Madrid- Editorial Civitas, 1997, p. 128. 
se medirían por su sentido expresado en la aplicación de la norma. A partir de allí, dado que no basta con un simple mensaje simbólico-comunicativo abstracto, sería necesario que la expresión de reproche jurídico-penal lleve aparejada además un "dolor penal" ("Strafleid"). Ello pues, como el mismo Јаковs lo expresó el año 2004 en la "Nordrhein-Westfälische Akademie der Wissenschaften": "Es palmario que el hecho de infligir dolor penal puede ser comprendido como símbolo de una contradicción; pues la destrucción o la limitación de la libertad del delincuente, es decir, la coacción dirigida contra él, muestra que su uso de libertad no puede sentar preceden$t e{ }^{43}$. Por consiguiente, el efecto del Derecho penal y, en particular, de la pena, se desplegaría única y exclusivamente en el campo de los daños a la vigencia de la norma, vale decir, en un plano simbólico manifestado tanto en lo abstracto cuanto en lo concreto. De ahí que, en suma, el dolor penal sirva para salvaguardar la vigencia cognitiva de la norma y, de este modo, coadyuve a concretar el sentido de la pena, esto es, "la contradicción de la negación de la vigencia de la norma por parte del delincuente" ${ }^{44}$.

Ahora bien, la confluencia de esta teoría con la posición adoptada por el profesor escocés Antony DuFf, resulta, según algunos autores, muy similar y hasta idéntica ${ }^{45}$. En efecto, según este autor, partiendo de una visión del Derecho penal no como prohibición sino como "declaración de determinados valores de la comunidad política"46, el "ius puniendi" estatal se dirigiría a los ciudadanos en términos de expresarles cuáles son o deberían ser sus valores como ciudadanos, esto es, declarando y definiendo los "mala in se" y los "mala prohibita", a objeto de conseguir precisamente una abstención e inhibición de ciertas conductas. De ahí que, a la hora de reclamar autoridad, el orden jurídico apele a las "buenas razones de los ciudadanos", esto es, a su condición de sujetos normativos racionales, que deberían asentir sobre el mensaje comunicativo

43 JAKOBS, Günther. La pena estatal: significado y finalidad. Trad. Manuel Cancio Meliá- Bernardo Feijoo Sánchez. Navarra: Thomson-Civitas, 2006, p. 135.

44

45 disuasión, cooperación y equidad. Madrid- Barcelona- Buenos Aires- Sao Paulo: Marcial Pons, 2016, p. 79.

46

Ibídem, p. 141.

Cfr. RODRIGUEZ HORCAJO, Daniel. Comportamiento humano y pena estatal: DUFF, R.A. Punishment, communication, and community. Oxford- New York: Oxford University Press, 2001, p. 80. 
de la norma cumpliendo sus mandatos. El fin del Derecho penal y, en particular, de la pena, no sólo buscaría por ende que los ciudadanos se abstengan de delinquir o no vuelvan a cometer nuevos ilícitos, sino que también "reconozcan y acepten los mandatos legales como justificados y se abstengan de cometer delitos por esa razón, o que los delincuentes reconozcan la ilicitud de sus crímenes pasados y se abstengan de crímenes futuros también por esa razón" ${ }^{47}$.

Con todo, como el mismo Duff señala, sería imprudente sostener un exclusivo propósito o función de la pena o del Derecho penal, pues, sería tan erróneo como propender una interpretación unívoca sobre los diversos sistemas jurídicos existentes ${ }^{48}$ : "no podemos", afirma DuFf, "entender un conjunto de prácticas institucionales con una historia tan larga y compleja -como las que constituyen el Derecho penal-en términos de un solo propósito o función" ${ }^{49}$. De ahí que resulte mucho más razonable, según su parecer, plantear una serie de propósitos a partir de una teoría normativa, vale decir, una teoría prescriptiva que superando el déficit monista o unidimensional de algunas posturas ${ }^{50}$, detente una pretensión crítica y de corrección respecto del "ius puniendi" estatal. Para ello, naturalmente, se debería considerar que el castigo, en cualquiera de sus formas, supone siempre que un sujeto haya actuado contra Derecho y que sea responsable, vale decir, que se pueda decir que merece un castigo por el delito cometido. Una vez sentadas dichas bases, a su juicio, surgiría recién la necesidad de identificar cuáles son las condiciones y las precondiciones de punibilidad ("liability"), que, por lo demás, facultarían para que ciertos ciudadanos,

47 DUFF, R.A. Punishment, communication, and community. Oxford- New York: Oxford University Press, 2001, p. 81.

${ }^{48}$ Cfr. DUFF, Antony. Responsibility, citizenship and criminal law. En: DUFF, R.A; GREEN, Stuart (editores), Philosophical Foundations of Criminal Law. Oxford- New York: Oxford University Press, p. 125, 2011. Ibídem.

50 Recuérdese, este este sentido, lo aseverado por Stratenwerth: "La pena tiene sin duda la función de anular simbólicamente el quebrantamiento del Derecho, y se puede presentar por ello, en la reflexión filosófica, como "la negación de la negación del Derecho", que Hegel vio en ella". Sin embargo, "ello no impide denominarla a la vez, más concretamente, como inferir el mal que ella representa para el condenado". STRATENWERTH, Günter. ¿Qué aporta la teoría de los fines de la pena?. Trad. Marcelo Sancinetti. Bogotá: Universidad Externado de Colombia, 1998, p. 32. 
en nombre y representación de la comunidad, se dirijan al infractor como un sujeto normativo responsable. El castigo, por consiguiente, se podría entender como un acto de comunicación moral; como un acto que obliga a tratar al infractor siempre como un "igual"; como un acto que se dirige de forma simbólica en contra del acusado a fin de producir en él comprensión, aceptación y arrepentimiento del mal que causós ${ }^{51}$. No se trataría, por tanto, de un simple proceso unidimensional de "expresión", sino más bien de un proceso "bidireccional" e interactivo de "comunicación" que se da entre agentes racionales y responsables ${ }^{52}$. El desafío para una teoría liberal del castigo, en suma, sería siempre demostrar cómo y de qué forma, a pesar del delito cometido, el infractor puede seguir siendo tratado como un "igual" dentro de la comunidad política que lo cobija.

\section{B) TEORÍAS EXPRESIVAS ORIENTADAS A LA PERSONA: COMUNICACIÓN CON EL AUTOR Y LA VÍCTIMA}

Como lo adelantamos, existen dos factores inherentes a la pena y que le dan su razón de ser: el mal y el reproche. La pena, en efecto, implica la causación de un mal a través del cual se expresa un dolor ("hard treatment"), esto es, un daño que desde el punto de vista fáctico busca poner a alguien en una situación desagradable. Pero no se trata sólo de

51 Cfr. DUFF, R.A. Can We Punish the Perpetrators of Atrocities?. En: BRUDHOLM, Thomas; CUSHMAN, Thomas (editores). The religious in responses to mass atrocity: interdisciplinary perspectives. Cambridge: Cambrigde University Press, p. 83, 2009.

52 Así, como señala Duff: "Punishment is often said to serve an expressive purpose: but we should. I think, rather talk of a communicative purpose. For talk of expression focuses on those who express: we express our condemnation of the offender's crime: he figures simply as the passive recipient of that condemnation. Expression is a one-way activity requiring only an object at whom it is directed. Communication, however, is a two-way activity requiring not a passive recipient, but a participant to whose understanding it appeals and from whom it seeks a response: I express things to others, but I communicate with them. Expression may seek only to make an emotional, unreasoned impact on the hearer, but communication addresses her as a rational agent. 'Communication' is, for this reason, a better slogan for punishment, as it is for law”. DUFF, R.A. Alternatives to Punishment - or Alternative Punishments?. En: GRAGG, Wesley (editor). Retributivism and its critics. Stuttgar: Franz Steiner Verlag, 1992, p. 51. 
una restricción coercitiva de derechos que se inflige deliberadamente en contra de quien cometió un delito. Se trata también de un reproche institucionalizado, que cumpliendo presupuestos procesales y materiales, intenta comunicar simbólicamente la desaprobación jurídico-social de la conducta lesiva: una censura que no sólo se dirige al autor, sino que también a la víctima del delito y a la sociedad. De ahí que el juicio ético-social de reprobación, junto con su concreta forma de comunicación, sean, según algunos autores, los cauces esenciales a través de los cuales se puede entender la pena como un "reproche merecido"53.

$\mathrm{Al}$ respecto, son bien conocidos los aportes que ha efectuado el profesor de la Universidad de Cambridge, Andrew von HiRsch. En efecto, según éste, que la pena exprese un reproche o una desaprobación es una cuestión casi evidente, más si se considera nuestra noción de justicia en la realidad cotidiana ${ }^{54}$ : los padres suelen amonestar a sus hijos cuando éstos "se portan mal"; los profesores reprenden a sus alumnos por "faltas cometidas en la sala de clases"; los militares castigan a sus subordinados cuando "no cumplen sus ordenes"; los jueces castigan a los criminales por los delitos que éstos han cometido. En todos estos casos, la capacidad de responder a la realización de un mal con una reprobación o censura, afirma von HiRsch, forma parte de una moralidad que considera a las personas responsables de sus actos ${ }^{55}$; que implica que quien realizó un hecho reprobado debe cargar con sus consecuencias. Sin embargo, a su juicio, el Derecho penal le confiere a la censura un rol mucho más peculiar, pues, a diferencia del simple reproche en contextos cotidianos, la sanción penal anuncia de antemano que determinadas categorías de conducta son punibles. No se trata, por ende, de una mera inflicción empírica o fáctica de un daño, sino de un reproche que intenta apelar con "buenas razones" acerca de lo indeseado de una conducta; de suministrar "prudential

53 Cfr. MAÑALICH, Juan Pablo. La pena como retribución. Segunda parte: La retribución como teoría el Derecho penal. Derecho Penal y Criminología, vol. $28, \mathrm{n}^{\circ} 83,2007$, pp. 75 ss.

54 Cfr. VON HIRSCH, Andrew. Censure and sanctions. Oxford- New York: Oxford University Press, 2003, pp. 1 ss.

55 Cfr. VON HIRSCH, Andrew. Proportionality in the philosophy of punishment: from "why punish?" to "how much?". Israel Law Review, vol. 25, n 3-4, pp. 561-562, 1991. 
reasons" en pos que el delincuente y otros miembros de la comunidad estatal se inhiban de delinquir ${ }^{56}$. De ahí que la justificación reprobatoria del castigo, esto es, su rol para expresar censura o reproche, implique una auténtica comunicación moral que se corresponde con personas que actúan orientadas del modo reclamado por la 1 ley ${ }^{57}$.

Sin embargo, la teoría de von Hirsch no puede ser considerada como preventiva, puesto que él entiende la consecución de tal fin sólo dentro del marco de la censura dirigida en contra del autor. En efecto, en su concepto, "una respuesta condenatoria a una conducta lesiva puede expresarse en un modo puramente (o principalmente) simbólico; o bien, en un modo en el que la reprobación se exprese a través de la imposición del dolor. La sanción penal es una respuesta de este último tipo. Se la prefiere a la respuesta puramente simbólica por su papel complementario como desincentivo. La función preventiva funciona así solo dentro del marco de la censura" ${ }^{58}$. Por consiguiente, según von Hirsch, el reconocimiento del papel central de reproche individual en contra del autor fortalecería la necesidad de racionalizar el "ius puniendi" no sólo a través de la culpabilidad, sino que también a través de la necesidad de encontrar un justo punto de equilibrio entre la gravedad de la pena y el merecimiento del reproche. De ahí la importancia de acentuar, en el marco del "quantum" de la pena, la trascendencia del principio de proporcionalidad como postulado esencial para distribuir castigos. Ello, pues, si las sanciones estatales adoptan forma punitiva, esto es, expresan censura y reproche, la severidad de las sanciones debería permitir reflejar, comparativamente hablando, que el sufrimiento que se expresa a través de la condena es justo y proporcionado ${ }^{59}$.

${ }^{56}$ Cfr. VON HIRSCH, Andrew. Retribución y prevención como elementos de justificación de la pena. En: ARROYO ZAPATERO, Luis y otros (coordinadores). Crítica y justificación del Derecho penal en el cambio de siglo. Cuenca: Ediciones Universidad de Castilla-La Mancha, 2003, p. 134.

Cfr. VON HIRSCH, Andrew; ASHWORTH, Andrew. Proportionate Sentencing: Exploring the Principles. Oxford: Oxford University Press, 2003, p. 31.

VON HIRSCH, Andrew. Censure and sanctions. Oxford- New York: Oxford University Press, 2003, p. 14.

59 Cfr. VON HIRSCH, Andrew. Proportionality in the philosophy of punishment: from "why punish?" to "how much?". Israel Law Review, vol. 25, n 3-4, 1991, p. 571. 
Ahora bien, para alcanzar tal objetivo se debería asegurar que la pena se gradúe en atención a la gravedad del delito, pues, a juicio de voN Hirsch, sólo así se podría asegurar una respuesta punitiva coherente y proporcionada para cada caso ${ }^{60}$. A partir de allí, existirían dos formas de entender la proporcionalidad: una ordinal y otra cardinal. Con la idea de "proporcionalidad ordinal", grosso modo, se intentaría aludir a la equivalencia entre las penas correspondientes a diferentes delitos, de modo que aquellas personas que hubieran cometido delitos equiparables reciban penas equiparables. Con la idea de "proporcionalidad cardinal", en cambio, se aludiría al punto inicial de "arranque" de una determinada escala o marco penal, a objeto de fijar las fronteras aproximadas de la cuantificación de la pena ${ }^{61}$. En consideración a ello, si la proporcionalidad goza de una preponderancia como la sugerida, las sanciones deberían variar su severidad de acuerdo con un cierto nivel de estandarización, pues, según von HiRsch, la exigencia de mantener tal proporcionalidad requeriría que seamos capaces de comparar la severidad, es decir, que seamos capaces de asumir que cuanto más original sea una condena, más difícil será su comparación ${ }^{62}$. De ahí que sean dos los ejes básicos para preconizar un cierto nivel de estandarización: por un lado, una concepción del daño basada en el estándar de vida, que apuntaría a analizar la forma como el delito lesiona los medios y capacidades que normalmente ayudan a la gente a conseguir una buena calidad de vida; y, por otro lado, una concepción de culpabilidad fundamentada en un reproche comunicativo, vale decir, en una comunicación que se dirige al autor como una agente

60 Por ello, según expresa von Hirsch: "By punishing one kind of conduct more severely than another, the punisher conveys the message that it is worse-which is appropriate only if the conduct is indeed worse (i.e. more serious)". VON HIR$\mathrm{SCH}$, Andrew. Censure and sanctions. Oxford- New York: Oxford University Press, 2003, pp. 15-16.

${ }^{61}$ Cfr. VON HIRSCH, Andrew. Proportionality in the philosophy of punishment: from “why punish?" to "how much?”. Israel Law Review, vol. 25, n 3-4, 1991, pp. 572 ss.

62 Ello reflejaría, por lo demás, el carácter convencional del grado de desaprobación que se expresa a través de delito. De ahí que, según von Hirsch: "When a penalty scale has been devised to reflect the comparative gravity of crimes, altering the scale's magnitude, by making pro rata increases or decreases, represent just a change in that convention". VON HIRSCH, Andrew. Censure and sanctions. Oxford- New York: Oxford University Press, 2003, pp. 19. 
moral que evalúa y asume responsablemente las consecuencias lesivas de su actuar. De este modo, a pesar que las directrices para conseguir dicha estandarización pueden variar y no ser necesariamente perfectas, la razón más obvia para defender tal convencionalismo sería relativamente simple: propender a la coherencia e igualdad en la aplicación de la penas, de modo que distintos jueces apliquen criterios de gravedad similares.

Con todo, a partir de los aportes efectuados por von Hirsch, un gran número de autores ha profundizado sus postulados expresivos no sólo en relación con el autor, sino que también en relación con la víctima y su conocido “redescubrimiento”. En efecto, según el profesor alemán Klaus GÜNTHER, a finales del siglo XX y luego de varias décadas de incertidumbre y cambios continuos, los contornos del Derecho penal parecen haber sido redefinidos en pos de superar la clásica "política penal preventiva”, esto es, aquella que sustentaba que el castigo sólo podía justificarse como un medio para aumentar el bienestar de la colectividad ${ }^{63}$. Ello, pues, a pesar que tal instrumentalismo tenía ciertos méritos, en especial para abrogar prohibiciones anticuadas e injustificadas, aquél no parecía tener ningún límite deontológico al criminalizar comportamientos disfuncionales o peligrosos, ni mucho menos una referencia moral plausible en relación con la víctima y el ofensor. Éste último, en efecto, era tratado como un mero objeto de la intervención preventiva; como una herramienta para medidas de seguridad pública a través del castigo y, en general, como un medio para la realización de fines políticos dentro de la legislación penal ${ }^{64}$. La víctima, en tanto, era vista como un sujeto desafortunado; una persona cuyos intereses estaban supeditados al "interés público" del persecutor penal y, por ende, que debía soportar impávidamente los efectos lesivos del delito ${ }^{65}$.

Tal visión, sin embargo, a juicio de GüNTHER, ha sido drásticamente modificada. Hoy día, en efecto, "hacer justicia en lugar de perseguir objetivos políticos con el castigo supone que el crimen se considera principalmente como una interacción moral entre dos personas morales y

63 Cfr. GÜNTHER, Klaus. Criminal law, crime and punishment as communication. Normative Orders Working Paper, nº 2, 2014, p. 2.

64

65 Cfr. Sobre ello GARLAND, David. The culture of control. Crime and social order in contemporary society. Chicago: The University of Chicago Press, 2002, pp. 11-12. 
autónomas: el delincuente como sujeto responsable, y la víctima como sujeto moral cuya autonomía e integridad es negada por el delincuente" ${ }^{66}$. De ahí que el tránsito del "instrumentalismo político" al "expresivismo moral" haya producido un "giro comunicativo" fundamental a favor del ofendido: un reconocimiento de que la víctima es un agente moral, un actor racional y comunicativo, que al igual que el infractor, tiene el derecho a ser tratado y considerado como detentador de una serie de potestades y facultades. No porque la víctima ostente "per se" un status comunicativo, sino porque es el crimen el que encierra una serie de actos con significado expresivo; una secuencia de actos lingüísticos que comienzan con la ley penal, la cual, sin mediar distinciones arbitrarias de ninguna especie, reclama autoridad sobre todos los ciudadanos al afirmar que hay buenas razones -fundamentadas en los valores de la comunidad-para que se eviten conductas consideradas como delictivas ${ }^{67}$.

Ciertamente, tales aseveraciones -a juicio de GüNTHER-sólo tendrían cabida en un sistema democrático y deliberativo, en el cual, los principios y las normas jurídico-penales, deberían ser asumidas como una manifestación de la autonomía política y una auto-comprensión de carácter republicano del sistema ${ }^{68}$; no desde una faz abstracta e impersonal, distanciada de los intereses reales de los ciudadanos, sino desde una óptica de la deliberación pública que considera los intereses individuales de sus miembros; desde un prisma que asume a todo ciudadano, víctimas e infractores, ofensores y ofendidos, como colegisladores de las deliberaciones públicas que dan lugar a la ley que los rige ${ }^{69}$. De ahí que cada

66 GÜNTHER, Klaus. Criminal law, crime and punishment as communication. Normative Orders Working Paper, ${ }^{\circ}$ 2, 2014, p. 3.

${ }_{67}$ Quizá por ello, como afirma Gunther: "I cittadini si assumono la responsabilità delle loro leggi penali. Ciò significa che la legislazione non è la somma casuale di decisioni e preferenze contingenti, che entrano nel processo politico già belle pronte. I cittadini pensano invece di poter reciprocamente giustificare e criticare le loro preferenze. In altre parole, essi si vedono come persone in grado di riflettere (e agire) alla luce di ragioni pubblicamente sostenibili". GÜNTHER, Klaus. Responsabilità e pena nello stato di diritto. Trad. Leonardo Ceppa. Torino: Trauben, 2010, p. 21.

68 Cfr. GÜNTHER, Klaus. Responsabilità e pena nello stato di diritto. Trad. Leonardo Ceppa. Torino: Trauben, 2010, p. 22.

69 Cfr. GÜNTHER, Klaus. Somente em uma sociedade humana todo ato tem seu autor. En: AA.VV. Responsabilidade e pena no estado democrático de direito. São Paulo: FGV Direito SP, 2016, p. 33. 
vez que se comete un delito se asuma no sólo un fracaso de las razones comunicativas trasmitidas por la ley, sino que también una negación y rechazo de la víctima en su condición de colegislador. El castigo puede entonces considerarse así, por tanto, como un complejo comunicativo de actos expresivos en el que interactúan el delincuente, la víctima y la sociedad en relación con las razones justificativas de la legislación y las razones injustificadas del delincuente.

\section{3.- LA REPARACIÓN A LA LUZ DE LAS TEORÍAS EXPRESIVAS DE LA PENA}

Según hemos podido advertir, las teorías expresivas orientadas hacia la persona comúnmente se sustentan en una doble fundamentación: la primera, que una legitimación completa de las intervenciones jurídico-penales no puede ser abordada satisfactoriamente sin distinguir entre el fundamento de la existencia del sistema punitivo y el fundamento de la imposición judicial de la pena; la segunda, que el juicio de desvalor referido al caso concreto puede y debe considerar una censura reprobatoria transmitida al delincuente, a la víctima y la sociedad.

Pues bien, tomando en cuenta tal caracterización, ¿̇ignifica ello una inclusión de la reparación como un equivalente funcional de la pena? ¿Puede producir la reparación real o simbólica efectos expresivos? ¿Bastará acaso un acuerdo conciliatorio entre víctima y ofensor para alcanzar tales fines? Para responder a dichas interrogantes, en principio, se deben descartar todas aquellas posturas que asumen a las teorías expresivas como meros intentos por legitimar los presupuestos de imputación penal ${ }^{70}$. Ello, pues, como se adelantó, desde tal óptica no sólo se descalifica el creciente número de elaboraciones surgidas a partir de tales teorías, sino que también se establece erradamente una única y exclusiva función a su respecto. De hecho, la adopción de una perspectiva expresiva puede servir para justificar no sólo la adscripción

70 Así, a juicio de Feijoo, “(...) los expresivistas no platean una auténtica teoría de la pena, sino que centran su interés en los presupuestos de una castigo legitimo, que en nuestra cultura jurídica denominamos culpabilidad por el hecho". FEIJOO SÁNCHEZ, Bernardo. La estabilidad normativa como fin de la pena: ¿puro teatro?. En: AA.VV. Estudios de Derecho Penal. Homenaje al profesor Santiago Mir Puig. Buenos Aires: B de F, 2018, p. 312. 
de responsabilidad frente a un concreto acontecer delictivo, sino que también incluso puede servir para legitimar y fundamentar el propio proceso penal. No en vano fue el mismo BELING quien llegó a sentenciar, que mientras el Derecho penal "no le toca al delincuente ni un solo pelo"71, el Derecho procesal penal debe lidiar con el individuo concreto; con la persona de carne y hueso que, en definitiva, deberá soportar una privación o restricción de sus derechos fundamentales más básicos. Piénsese, en este sentido, en la aflicción que implica una medida intrusiva decretada en la marcha de una investigación penal, o bien en la aplicación de una medida cautelar de prisión preventiva ordenada para el supuesto éxito de una investigación. En todos estos casos, y en especial, en éste último, si bien existe una dimensión expresiva y simbólica anterior al juicio de culpabilidad, el sujeto que las experimenta sufre empíricamente un mal que se tranforma en un signo inequívoco de reprobación sancionatoria. De allí, entonces, que el proceso penal desempeñe una importante función expresiva y comunicativa, que se orienta desde una "perspectiva integral del sistema penal" en una doble dimensión: por un lado, a través de un conjunto de actos destinados al esclarecimiento de la verdad probable de los enunciados fácticos considerados delictivos; $y$, por otro, a través del reconocimiento de una serie de garantías que limitan el ejercicio del "ius puniendi" estatal. De este modo, si se toma en serio el delito como la falta de lealtad comunicativa frente a la defraudación de la norma de conducta, debería admitirse que dicha faz comunicativa continúa produciendo sus efectos en el proceso penal, puesto que es precisamente a través de él que cobran materialidad todos y cada uno de los criterios decisivos para la aplicación de la respectiva norma-sanción.

Es más, como argumenta FEELEY, por más que pretendamos establecer una división radical entre el "proceso" y la "pena", la mayoría de las actuaciones procesales anteriores y preparatorias al juicio oral, tales como la prisión preventiva, las comparecencias judiciales reiteradas, las cauciones reales y económicas decretadas, así como su excesiva duración y dilación en el tiempo, pueden llegar a constituir circunstancias tan gravosas que incluso pueden resultar más nocivas que la propia pena que se llegue

71 BELING, Ernst. Derecho Procesal Penal. Trad. Miguel Fenech. Barcelona: Ed. Labor, 1943, p. 2. 
a imponer ${ }^{72}$. De ahí que el proceso penal no sólo desempeñe una función estabilizadora desde una faz simbólica y comunicativa, sino que también pueda llegar a entrañar un genuino "hard treatment". No por nada, por ejemplo, tratándose de la medida cautelar de prisión preventiva, reconociéndose su expresividad y carácter empíricamente aflictivo, es posible constatar una práctica generalizada en orden a considerar el denominado abono "propio", "estricto" u "homogeneo", en cuya virtud, el tiempo que un individuo permaneció sujeto a tal medida cautelar, se imputa a la pena privativa de libertad que se imponga por sentencia condenatoria. De ahí que, por lo tanto, a pesar que tales medidas no constituyan estrictamente una pena, sí provoquen un significativo detrimento personal y patrimonial, que, atento el "principio de proporcionalidad", dan pie no sólo para avalar una eventual reducción del "quantum" de pena decretada, sino que también, incluso, si no se justifica adecuadamente su imposición, a considerar una eventual acción civil indemnizatoria por error judicial.

Pues bien, sentado lo anterior, cabe destacar que existen algunos autores que niegan cualquier tipo de efecto expresivo a la reparación, mientras que otros lo consideran sólo bajo ciertas circunstancias y presupuestos.

Desde la primera óptica, a juicio de la profesora de la Universidad de Humboldt Tatjana HörnLE, si bien los intereses legítimos de las víctimas constituyen un componente que ninguna teoría de la pena puede rechazar, esto no significa que frente a la comisión de un injusto-culpable se pueda renunciar a la imposición de un mal a través de la reparación. En efecto, a juicio de HörnLE, la característica expresiva de la pena es ampliamente reconocida en los contextos de las sociedades modernas y, como tal, supone un elemento que transmite una desaprobación social frente a una conducta criminosa $^{73}$. No se trata, por consiguiente, de un mero intento

72 Por consiguiente, "when we view criminal sanctioning from this broader, functional perspective, the locus of court-imposed sanctioning shifts dramatically away from adjudication, plea bargaining, and sentencing to the earlier pretrial stages. In essence, the process itself is the punishment”. FEELEY, Malcolm. The Process is the Punishment: Handling Cases in a Lower Criminal Court. New York: Russell Sage Foundation, 1992, p. 30.

73 Cfr. HÖRNLE, Tatjana. Distribution of punishment: the role of a victim's perspective. Buffalo Criminal Law Review, vol. 3, n 1, 1999, p. 178. 
disuasorio e instrumental en pos de favorecer una inhibición delictiva, sino de reconocer que el castigo expresa una censura en tanto componente esencial de nuestras actitudes interpersonales de comunicación. Sin embargo, a juicio de dicha autora, la extensión de tal reproche no se basta a sí misma, sino que requiere de la imposición de un concreto dolor penal ${ }^{74}$. Ello, pues, según su parecer, "en nuestra tradición de procedimientos penales, la desaprobación se expresa no como un acto formal separado, sino a través de la imposición de la sanción al final del juicio". De esta forma, siguiendo muy de cerca las ideas de FEINBERG ${ }^{75}$, según HörnLE, lo usual será que la propia irrogación del mal desempeñe la función de expresar reproche y censura, de forma tal que dicho "tratamiento severo" se transforme en un símbolo inequívoco de reprobación pública ${ }^{76}$. De ahí que, por tanto, el reproche y la irrogación del mal estén entrelazados con el efecto de la severidad de la sanción y, de este modo, se transmitan al ofensor de forma proporcional a la magnitud de su injusto-culpable realizado ${ }^{77}$.

Con todo, a juicio de Hörnle, dicha comunicación no sólo se dirige al autor, sino que también -y preferentemente- al ofendido por el delito. En efecto, según su parecer, si la sanción penal sólo persiguiese como fin una declaración de culpabilidad de la conducta ilícita del infractor, bastaría inequívocamente una declaración pública en tal sentido y todo volvería a la normalidad. Sin embargo, las cosas no son así. La

74 En un sentido similar, según Pawlik: "el actuar de personas racionales tiene siempre una dimensión comunicativa. Por ello, la aseveración de que también el acto punitivo tiene una dimensión comunicativa no resulta en absoluto sorprendente. Ésta es una declaración general propia de la teoría de la acción y no genuinamente jurídico-penal. Ahora bien (...), evidentemente, la pena es además dolor, y ello plantea el problema de la justificación de dicho dolor". PAWLIK, Michael. Ciudadanía y Derecho penal. Fundamentos de la teoría de la pena y del delito en un Estado de libertades. Trad. Ricardo Robles Planas y otros. Barcelona: Atelier, 2016, p. 62.

75 Así, según Feinberg: "To say that the very physical treatment itself expresses condemnation is to say simply that certain forms of hard treatment have become the conventional symbols of public reprobation". FEINBERG, Joel. "The expressive function of punishment". The Monist, vol. 49, nº 3 (1965), p. 402.

76 Cfr. HÖRNLE, Tatjana. Distribution of punishment: the role of a victim's perspective. Buffalo Criminal Law Review, vol. 3, nº 1, 1999, p. 178.

77 HÖRNLE, Tatjana. Distribution of punishment: the role of a victim's perspective. Buffalo Criminal Law Review, vol. 3, nº 1, 1999, pp. 178-179. 
desaprobación formal encarnada en la imposición de un "tratamiento severo" confirma que la víctima fue agraviada por medio del hecho en cuestión; que el injusto-culpable no fue fruto del azar ni de una simple circunstancia del acaso, sino que se debe a un acto deliberado y consciente que merece y necesita pena. De ahí que la condena deba contener no sólo fundamentos referentes a la extensión y ámbito de protección de los derechos del infractor, sino que también un juicio sobre la extensión de los derechos de la víctima y sobre la demarcación entre su esfera de protección y la del delincuente. Esto significa reconocer que para el Derecho penal la víctima no es un sujeto desdichado que debe soportar los efectos perniciosos del delito, sino, todo lo contrario: que tiene el derecho a no aceptar la conducta del delincuente y, como tal, a jugar un rol relevante en la determinación de la responsabilidad del agente, en la determinación de la gravedad de la ofensa y en la fijación del "quantum" de la pena. De este modo, a juicio de HörnLe, si bien el proceso penal no sirve como tratamiento psicológico o soporte emocional a favor de la víctima, sí cumple una función expresiva de restablecimiento del Derecho frente al "vacío comunicativo" generado por la comisión del delito.

Ahora bien, asumiendo que la seriedad de una declaración se logra sólo mediante el apoyo simbólico en forma de privación de bienes, según HÖRNLE, "desde la perspectiva de las víctimas sería insuficiente la corroboración del juicio de desvalor solamente mediante la reparación del daño o la indemnización"78. Ello, pues, según la autora germana, "la reparación del daño solamente devuelve el statu quo económico a su estado anterior al hecho, de manera que aquella no constituye una genuina causación de un mal. La indemnización también es insuficiente para aclarar el juicio de desvalor en caso de lesiones graves de derechos, puesto que mediante una perdida solamente económica no es posible explicar un reproche importante"79. De este modo, si se considera la causación de un mal como refuerzo y diferenciación del acto comunicativo de reproche, según su parecer, se perdería la lógica de entender que la sanción penal entraña a los dos factores de forma

78 HÖRNLE, Tatjana. Teorías de la pena. Trad. Nuria Pastor. Bogotá: Universidad Externado de Colombia, 2015, p. 43.

79 HÖRNLE, Tatjana. Teorías de la pena. Trad. Nuria Pastor. Bogotá: Universidad Externado de Colombia, 2015, p. 43. 
mancomunada y, por consiguiente, de comprender que la irrogación del mal y el juicio de reproche son elementos funcionales en pos de un mismo contenido expresivo ${ }^{80}$. La renuncia a un juicio estatal de desvalor en aras de una reparación, por tanto, contendría un mensaje implícito cuyo contenido comunicativo sería: el delito no fue lo suficientemente grave e importante para la víctima, de forma tal que lo único que le resta es la posibilidad de acudir a un procedimiento diverso al penal.

Desde un enfoque diverso, en un intento por disociar la expresión del reproche de la irrogación del mal y, de este modo, dar cabida a procedimientos de tipo restaurativo, destaca la posición del profesor de la Universidad de Minnesota Antony Duff. En efecto, según éste, los teóricos restauradores tienen razón al insistir en que nuestras respuestas al crimen deben tender a la "reparación", mientras que también los teóricos retributivos tienen derecho a argumentar que siempre se debe buscar que los delincuentes sufran el castigo que merecen ${ }^{81}$. Sin embargo, explica DufF, ambas posturas yerran al suponer que sus planteamientos son incompatibles. Ello, pues, la restauración no sólo es compatible con la retribución, sino que incluso necesita de ésta última, puesto que el tipo de restauración que el crimen reclama -dadas las características profundas de nuestra vida social- sólo puede lograrse mediante un castigo retributivo. En efecto, lo que el delincuente merece y recibe en este tipo de procedimiento es precisamente lo que se le exige al participar en un debate de tipo

80 Así, según Hörnle: "Even if the number of murders or rapes drops to 1 \% of the current rates, it would still be necessary to retain criminal punishment. With regard to serious crimes against persons, victims have a legitimate interest in the states' expression of not only formal but serious enough censure which requires some form of hard treatment. Merely verbal disapproval unavoidably has the meaning of 'mild disapproval"'. HÖRNLE, Tatjana. Theories of Criminalization. Comments on A.P. Simester/Andreas von Hirsch: Crimes, Harms and Wrongs. On the Principles of Criminalisation. Hart Publishing: Oxford and Portland, Oregon. 2011. Criminal Law \& Philosophy, vol. 10, $\mathrm{n}^{\circ} 2$ 2, 2016, p. 302. En sentido similar, aunque no idéntico, Cfr. MAÑALICH, Juan Pablo. Retribucionismo expresivo. Acerca de la función comunicativa de la pena. En: KINDHÄUSER, Urs; MAÑALICH, Juan Pablo. Pena y culpabilidad en el Estado democrático de Derecho. Montevideo- Buenos Aires: B de F, 2011, pp. 40-41.

81 Cfr. DUFF, Antony. Restoration and retribution. En: VON HIRSCH, Andrew; ROBERT, Julian V; BOTTOMS, Anthony (editores). Restorative justice and criminal justice. Competing or reconcilable paradigms?. Portland: Hart Publishing, 2003, p. 43. 
conciliatorio: la realización de una serie de actos de reparación -materiales y simbólicos- dotados de un significado comunicativo de reconocimiento, perdón y reconciliación ${ }^{82}$. En este caso, expresa DufF, no tenemos que distinguir el sufrimiento que el tribunal impone como castigo, por un lado, de los sufrimientos constructivos no intencionados que el delincuente atravesaría en sus acciones de restitución frente a la víctima, por otro lado. Esto porque tales acciones reparadoras son diseñadas de forma dolorosa y son en sí mismas constitutivas del castigo del infractor ${ }^{83}$. De ahí que, al contrario de lo que se piensa, la reparación penal se caracterice como una práctica que incorpora flexiblemente elementos de justicia retributiva y de rehabilitación, pero que, al mismo tiempo, da cuenta también de elementos propios y originales que la dotan de un sentido único. Más concretamente, como sostiene DALY, "las prácticas de justicia restaurativa se centran en el delito y el delincuente; les preocupa censurar el comportamiento pasado y cambiar el comportamiento futuro; se ocupan de sanciones o resultados que son proporcionales y también "hacer las cosas bien" en casos individuales" ${ }^{4}$.

Ahora bien, según Duff, una vez que reconocemos que el infractor ha hecho algo malo, podemos identificar a lo menos tres tipos de reacciones "merecidas" en virtud de ese mal: el arrepentimiento del delincuente, su posible rehabilitación y, muy especialmente, la reconciliación con la víctima y la comunidad ${ }^{85}$.

El arrepentimiento es, según su parecer, un objetivo interno de reprobación o censura. Cuando censuramos a otros por sus malas acciones, nuestra intención o esperanza como comunidad es que acepten esa censura como justificada. Pero aceptar la censura como justificada supone reconocer y

82 Cfr. DUFF, R.A. Punishment, Communication, and Community. Oxford- New York: Oxford University Press, 2001, p. 96.

83 Cfr. DUFF, Antony. Restoration and retribution. En: VON HIRSCH, Andrew; ROBERT, Julian V; BOTTOMS, Anthony (editores). Restorative justice and criminal justice. Competing or reconcilable paradigms?. Portland: Hart Publishing, 2003, p. 51.

84 DALY, Kathleen. Revisiting the relationship between retributive and restorative justice. En: STRANG, Heather; BRAITHWAITE, John (editores). Restorative justice: philosophy to practice. Burlington- Vermont: Ashgate Publishing, 2000, p. 35.

85 Cfr. DUFF, R.A. Punishment, Communication, and Community. Oxford- New York: Oxford University Press, 2001, pp. 107 ss. 
aceptar que algo se hizo mal, vale decir, asumir el error por el cual se aplicó la censura penal, sumado a un reconocimiento auténtico de que se procedió mal. El arrepentimiento es por ello necesariamente doloroso e incomodo, pero al tratar de inducir al arrepentimiento, el castigo apunta a hacer que los delincuentes sufran precisamente los dolores del arrepentimiento y el remordimiento.

Sin embargo, a juicio de Duff, si vamos a dirigirnos a los delincuentes como agentes morales responsables, si nos comprometemos en un esfuerzo apropiado de persuasión "transparente", deberíamos también buscar inducir "su reforma". En efecto, reconocer y arrepentirme del mal causado es también reconocer la necesidad de evitar cometer ese mismo error en el futuro. Rechazar el delito es, por consiguiente, también comprometerme a tratar de evitar repetirlo. De ahí que un proceso de censura o castigo destinado a inducir el arrepentimiento, también deba tener como objetivo primordial el inducir a la rehabilitación: no intentar moldear al delincuente a nuestros deseos como sociedad, sino de convencerlo de la necesidad de reformarse para su propia conveniencia.

Quizás por ello, el corolario de un arrepentimiento sincero y de una reforma coherente, sea precisamente la reconciliación del ofensor con la víctima y la sociedad. Luego, no se trata de una reconciliación apologética que tome necesariamente una determinada forma de corporeidad, sino más bien de formas de reparación que expresen un auténtico y genuino arrepentimiento del mal que se causó con el delito. De ahí que, según DuFf, debiésemos ver a la mediación penal y la reparación no como una instancia expresiva sino comunicativa. Ello, pues, la instancia expresiva se enfoca unidireccionalmente sólo en aquellos que expresan, esto es, expresamos nuestra condena por el delito del delincuente: él figura simplemente como el receptor pasivo de esa condena. Sin embargo, la comunicación es una actividad bidireccional que no requiere un receptor pasivo, sino un participante a cuyo entendimiento se apela y de quien se busca una respuesta de arrepentimiento, reforma y reconciliación. La comunicación es, por esta razón, un mejor eslogan para el acuerdo obtenido por la víctima y el ofensor como agentes racionales en una posible reparación ${ }^{86}$.

${ }^{86}$ Cfr. DUFF, R.A. Alternatives to Punishment - or Alternative Punishments? En: GRAGG, Wesley (editor). Retributivism and its critics. Stuttgar: Franz Steiner Verlag, 1992, p. 51. 
Así pues, la mediación penal como vía idónea para conseguir una reparación justa, expresa DuFf, "efectivamente se ajusta a las definiciones estándar de castigo, como algo intencionalmente doloroso u oneroso impuesto a un delincuente por su delito, por alguna persona u organismo con la autoridad para hacerlo, $y$, podemos agregar, destinado a comunicar la censura por ese delito" ${ }^{87}$. En efecto, según el profesor escocés, la mediación penal se deriva de la exigencia kantiana de respetar a los individuos como agentes racionales y autónomos: pues, respetar a otro es tratarlo no sólo como un objeto cuyo comportamiento queremos controlar, sino como un sujeto que al que debemos dirigirnos mediante modos apropiados de comunicación y argumentación. La mediación penal pretende ser, por consiguiente, un proceso comunicativo que involucra múltiples objetivos. En primer lugar, porque constituye un procedimiento diseñado para enfrentar a los delincuentes con los efectos de su ofensa, que intenta influir de manera constructiva en su comportamiento futuro, de manera de fomentar su sentido de responsabilidad y comprensión acerca de la necesidad de evitar el crimen y sus perniciosas consecuencias. En segundo lugar, porque dicho procedimiento también otorga a la víctima y al agresor un papel central y participativo en la respuesta a su crimen, es decir, en la búsqueda de soluciones que fomentan la compensación y el restablecimiento en lugar de las represalias, lo cual conduce a que el delincuente emprenda acciones efectivas de reparación en favor de la víctima. Y, en tercer lugar, porque tal paradigma contribuye a la reintegración del delincuente a la normalidad de sus relaciones sociales, proporcionando una oportunidad para que asuma su responsabilidad y se arrepienta del injusto cometido, de forma tal de asegurar que el mal que se acuerde sea proporcional a la gravedad de la ofensa.

De esta forma, la justicia restaurativa en general, y la mediación penal en particular, según DufF, constituirían una forma especial de "penitencia secular" ${ }^{\prime 2}$. Esto, pues, la idea de penitencia ayudaría a explicar

87 DUFF, Antony. Restoration and retribution. En: VON HIRSCH, Andrew; ROBERT, Julian V.; BOTTOMS, Anthony (editores). Restorative justice and criminal justice. Competing or reconcilable paradigms?. Portland: Hart Publishing, 2003, p. 53.

88 Sobre la distinción entre penitencia secular y religiosa, Cfr. DUFF, R.A. Penance, punishment and the limits of community. Punishment and Society, vol. 5, no 3, pp. 295-312, 2003. 
el papel del "tratamiento duro" de la reparación: por un lado, porque una penitencia es, idealmente hablando, un castigo que un malhechor se impone a sí mismo, vale decir, una carga dolorosa a la que se somete voluntariamente porque ha hecho algo malo; y, por otro lado, porque tal proceso penitencial permitiría el encuentro entre el delincuente y sus víctimas a fin de manifestar arrepentimiento, remordimiento y reforma. En suma, el procedimiento restaurativo sería tanto reformativo como reconciliatorio: si el delincuente se arrepiente de su delito, debe reconocer la necesidad de reformar su conducta futura y, de este modo, manifestar actos de reparación a través de los cuales pueda reconciliarse con sus víctimas y, por intermedio de ellas, con toda la comunidad.

\section{Consideraciones finAles}

A través de estas líneas hemos tratado de denotar los aspectos más relevantes de la reparación por el hecho punible, a favor de la víctima, bajo el supuesto de las denominadas "teorías expresivas de la pena". A partir de ello, en términos generales, hemos podido advertir que no existe una única visión a su respecto ni tampoco un genuino postulado que aglutine sus diversas manifestaciones. De hecho, las teorías expresivas de la pena pueden servir para legitimar y fundamentar no sólo las penas o las medidas de seguridad, sino que también a la reparación en cuanto tercera vía autónoma de sanción penal. Ello, pues, más allá que la reconciliación y la compensación de daños aporten beneficios para todos los afectados por el conflicto jurídico-penal, su concreta configuración pretende alcanzar una superación del injusto, un restablecimiento del Derecho, que ha de tener lugar no sólo a costa de autor, sino que también de la víctima y la sociedad.

Así las cosas, a razón de todo lo señalado, resulta posible extraer las siguientes conclusiones:

$1^{\circ}$ Que la reparación puede involucrar, en efecto, el reconocimiento de la autoría del hecho generador del daño, del mismo modo que también puede transmitir a la población la confianza en que la paz jurídica perturbada por el delito se restablece.

$2^{\circ}$ Que, sin embargo, dicha rectificación del hecho y manifestación de acatamiento de la norma, deben ir acompañadas necesariamente de 
actos de reparación total o parcial, real o simbólica, que permitan comprender que el autor ha realizado un esfuerzo superior al jurídicamente exigible en orden a compensar el daño causado a la víctima. De ahí que la reparación no se baste sólo como un acto del habla, como una mera declaración, como una expresión de voluntad, sino que requiera de un genuino "dolor penal" del infractor a fin de contribuir a profundizar en su concreto arrepentimiento.

$3^{\circ}$ Que, por consiguiente, independientemente que la reparación no sea impuesta sino acordada, cualquier forma de compensación del daño o de mitigación de sus efectos, sea por la vía de la restitución, de la indemnización de perjuicios, o incluso de la realización de trabajos en beneficio de la comunidad, debe traducirse en un mal que dote a las prestaciones reparadoras del carácter aflictivo que supone su comprensión como sanción.

$4^{\circ}$ Que, en todo caso, ello no quiere decir que la reparación pueda sustituir a la pena y sus conocidos efectos expresivos. En efecto, tal y cual como lo expusimos, el elemento de "tratamiento severo" en las sanciones penales proporciona, "ex ante", una razón prudencial para el abandono de la ofensa, puesto que a través de su criminalización el Estado transmite que la conducta es incorrecta y, por lo tanto, suministra razones prudenciales para que cualquier agente moral se abstenga de realizar la conducta de que se trata. Sin embargo, la conducta humana supone un proceso interactivo complejo, que involucra tanto una capacidad para el razonamiento moral, así como fuertes instintos e inclinaciones hacia la nocividad. Los seres humanos, por ende, somos criaturas morales pero falibles, capaces de ser motivados por apelaciones normativas, pero a veces, también, con la capacidad de producir graves ofensas a nuestros mismos congéneres.

$5^{\circ}$ De ahí que, por tanto, no se pueda renunciar a la pena en favor de la reparación, dado el alto déficit fáctico y comunicativo que ésta ultima presenta tratándose de casos de gran lesividad. De este modo, si bien la reparación puede contribuir a perseguir los fines propios del Derecho penal, ésta solo se puede concretar desde una perspectiva de la subsidiariedad: esto es, reduciendo a la pena al mínimo imprescindible, de forma tal de recurrir a ella sólo en casos de extrema gravedad y necesidad. 


\section{REFERENCIAS BIBLIOGRÁFICAS}

ALASTUEY DOBÓN, M. Carmen. La reparación a la víctima en el marco de las sanciones penales. Valencia: Tirant lo Blanch, 2000.

ALBRECHT, Peter-Alexis. La funcionalización de la víctima en el sistema de justicia penal. En: AA.VV. La víctima en el sistema penal. Dogmática, proceso y política criminal. Trad. Luis Reyna Alfaro. Lima: Grijley, 2006, p. 41-58.

ALCÁCER GIRAO, Rafael. La mediación penal y la atenuante de reparación: similitudes y criterios de aplicación. En, AA.VV. Justicia restaurativa, mediación penal y penitenciaria: un renovado impulso. Madrid: Reus, 2011, p. 109-126.

BELING, Ernst. Derecho Procesal Penal. Trad. Miguel Fenech, Barcelona: Ed. Labor, 1943.

BENN, S.I.; PETER, R.S. Social Principles and the democratic state. London: Allen \& Unwin, 1959.

BERMAN, Mitchell. Two kinds of retributivism. En: DUFF, R.A; GREEN, Stuart P (editores). Philosophical foundations of criminal law. Oxford: Oxford University Press, p. 433-457, 2011. https://doi.org/10.1093/ acprof:oso/9780199559152.003.0019

BIBAS, Stephanos; BIERSCHBACH, Richard A. Integrating remorse and apology into criminal procedure. The Yale Law Journal, vol. 114, nº 84, p. 85-148, 2004. https://doi.org/10.2307/4135717

BOOMIN, David. The problem of punishment. Cambridge: Cambridge University Press, 2008.

COEN, R. The Rise of the victim- A Path to punitiveness?. Irish Criminal Law Journal, no 16,2006 , p. 10-14.

CORNACCHIA, Luigi. Vittime e giustizia criminale. Rivista Italiana di Diritto e Procedura Penale, fasc. 4. Milano: Giuffrè, 2013, p. 1760-1793.

CRAGG, Wesley. The practice of punishment: towards a theory of restorative justice. Londres- New York: Routledge, 1992.

DALY, Kathleen. Revisiting the relationship between retributive and restorative justice. En: STRANG, Heather; BRAITHWAITE, John (editores). Restorative justice: philosophy to practice, Burlington- Vermont: Ashgate Publishing, 2000, p. 33-54. 
DOAK, Jonathan; HENHAM; Ralph; MITCHELL, Barry. Victims and the sentencing process: developing participatory rights?. Legal Studies, vol. 29, n 4, p. 651-677, 2009. https://doi.org/10.1111/j.1748-121X.2009.00134.x

DUFF, Antony. Responsibility, citizenship and criminal law. En: DUFF, R.A; GREEN, Stuart (editores), Philosophical Foundations of Criminal Law. Oxford, Oxford University Press, pp. 125-148, 2011. https://doi.org/10.1093/ acprof:oso/9780199559152.003.0007

DUFF, Antony; GARLAND, David. Thinking about Punishment. En: DUFF, Antony; GARLAND, David (editores), A Reader on Punishment. Oxford, Oxford University Press, 1994. p. 1-43.

DUFF, Antony. Restoration and retribution. En: VON HIRSCH, Andrew; ROBERT, Julian V; BOTTOMS, Anthony (editores). Restorative justice and criminal justice. Competing or reconcilable paradigms?. Portland: Hart Publishing, 2003, p. 43-60.

DUFF, R.A. Alternatives to Punishment - or Alternative Punishments?. En: GRAGG, Wesley (editor). Retributivism and its critics. Stuttgar: Franz Steiner Verlag, 1992, p. 43-68.

DUFF, R.A. Can We Punish the Perpetrators of Atrocities?. En: BRUDHOLM, Thomas; CUSHMAN, Thomas (editores). The religious in responses to mass atrocity: interdisciplinary perspectives. Cambridge: Cambrigde University Press, p. 79-104, 2009. https://doi.org/10.1017/cbo9780511575730.005

DUFF, R.A. Penance, punishment and the limits of community. Punishment and Society, vol. 5, nº 3, p. 295-312, 2003. https://doi.org/10.1177/1462474503005003004

DUFF, R.A. Punishment, communication, and community. Oxford- New York: Oxford University Press, 2001.

DURÁN MIGLIARDI, Mario. Introducción a la ciencia jurídico-penal contemporánea. Santiago de Chile: Ediciones Jurídicas de Santiago, 2006.

EREZ, Edna; TONTODONATO, Pamela. The effect of victim participation in sentencing on sentence outcome. Criminology, vol. 28, n ${ }^{\circ} 3$, p. 451-474, 1990. https://doi.org/10.1111/j.1745-9125.1990.tb01334.x

ESER, Albin. Acerca del renacimiento de la víctima en el procedimiento penal. Tendencias nacionales e internacionales. En: AA.VV. De los delitos y las víctimas. Buenos Aires: Ad-Hoc, 1992, p. 15-52.

ESER, Albin. Sobre la exaltación del bien jurídico a costa de la víctima. Trad. Manuel Cancio Meliá. Bogotá: Universidad Externado de Colombia, 1998. 
FEELEY, Malcolm. The Process is the Punishment: Handling Cases in a Lower Criminal Court. New York: Russell Sage Foundation, 1992.

FEIJOO SÁNCHEZ, Bernardo. La estabilidad normativa como fin de la pena: ¿puro teatro?. En: AA.VV., Estudios de Derecho Penal. Homenaje al profesor Santiago Mir Puig, Buenos Aires: B de F, 2018, p. 309-321.

FEINBERG, Joel. The expressive function of punishment. The Monist, vol. 49, $\mathrm{n}^{\mathrm{o}}$ 3, p. 397-423, 1965. https://doi.org/10.5840/monist196549326

FERRAJOLI, Luigi. Derecho y razón: teoría del garantismo penal. 6ta edición. Madrid: Trotta, 2004.

FLEW, Antony. The justification of punishment. Philosophy, vol. 29, p. 291-307, 1954. https://doi.org/10.1017/s0031819100067152

GARCÍA-PABLOS DE MOLINA, Antonio. Análisis criminológico de los diversos modelos y sistemas de reacción al delito. En: AA.VV. El nuevo Código Penal: presupuestos y fundamentos: (libro homenaje al profesor Doctor Don Angel Torío López). Granada: Comares, 1999, p. 135-160.

GARLAND, David. The culture of control. Crime and social order in contemporary society. Chicago: The University of Chicago Press, 2002.

GARRO CARRERA, Enara. La atenuante de reparación del daño. En: GARRO CARRERA, Enara; ASUA BATARRITA, Adela. Atenuantes de reparación y de confesión: equívocos de la orientación utilitarista. Valencia: Universidad del País Vasco- Tirant lo Blanch, 2008, p. 19-77.

GIMÉNEZ ALCOVER, Pilar, El Derecho en la teoría de la sociedad de Niklas Luhmann. Barcelona, Bosch Editor, 1993.

GÓMEZ COLOMER, José Luis. Estatuto jurídico de la víctima del delito. (La posición jurídica de la víctima del delito ante la justicia penal. Un análisis basado en el Derecho comparado y en las grandes reformas españolas que se avecinan). Pamplona: Thomson Reuters Aranzadi, 2014.

GÜNTHER, Klaus. Criminal law, crime and punishment as communication. Normative Orders Working Paper, $\mathrm{n}^{\circ}$ 2, 2014, p. 1-22.

GÜNTHER, Klaus. Somente em uma sociedade humana todo ato tem seu autor. En: AA.VV. Responsabilidade e pena no estado democrático de direito. São Paulo: FGV Direito SP, 2016, p. 15-36.

GÜNTHER, Klaus. Responsabilità e pena nello stato di diritto. Trad. Leonardo Ceppa. Torino: Trauben, 2010. 
HART, H.L.A. Punishment and responsibility. Essays in the philosophy of law. 2da edición. Oxford: Oxford University Press, 2008.

HIRSCH, Hans Joachim. La reparación del daño en el marco del Derecho penal material. En: AA.VV. De los delitos y de las víctimas. Trad. Elena Carranza. Buenos Aires: Ad-Hoc, 1992, p. 55-90.

HÖRNLE, Tatjana. Distribution of punishment: the role of a victim's perspective. Buffalo Criminal Law Review, vol. 3, $\mathrm{n}^{\circ}$ 1, p. 175-209, 1999. https://doi. org/10.1525/nclr.1999.3.1.175

HÖRNLE, Tatjana. Theories of Criminalization. Comments on A.P. Simester/ Andreas von Hirsch: Crimes, Harms and Wrongs. On the Principles of Criminalisation. Hart Publishing: Oxford and Portland, Oregon. 2011. Criminal Law \& Philosophy, vol. 10, n 2, 2016, p. 301-314.

HÖRNLE, Tatjana. Teorías de la pena. Trad. Nuria Pastor. Bogotá, Universidad Externado de Colombia, 2015.

HUBER, Bárbara. Sanciones intermedias entre la pena de multa y la pena privativa de libertad (Sobre la discusión en tomo a las penas ambulatorias y de contenido comunitario). Anuario de Derecho Penal y Ciencias Penales, vol. XLVII (1994), p. 155-176.

JAKOBS, Günther. Derecho penal. Parte general: fundamentos y teoría de la imputación. $2^{a}$ edición. Trad. Joaquín Cuello Contreras y José Luis Serrano González de Murillo. Madrid, Marcial Pons, 1997.

JAKOBS, Günther. Sobre el tratamiento de los defectos volitivos y de los defectos cognitivos. En: JAKOBS, Günther, Estudios de Derecho penal. Trad. Enrique Peñaranda Ramos y otros. Madrid: Ediciones Universidad Autónoma de MadridEditorial Civitas, 1997, p. 128-146.

JAKOBS, Günther. La pena estatal: significado y finalidad. Trad. Manuel Cancio Meliá y Bernardo Feijoo Sánchez. Navarra: Thomson-Civitas, 2006.

LACEY, Nicola; PICKARD, Hanna. To blame or to forgive? Reconciling punishment and forgiveness in criminal justice. Oxford Journal of Legal Studies, vol. 35, $\mathrm{n}^{\circ} 4$, 2015, p. 688 ss. https://doi.org/10.1093/ojls/gqv012

LARRAURI PIJOÁN, Elena. Justicia restauradora y violencia doméstica. En: ASUA BATARRITA, Adela; GARRO CARRERA, Enara (editoras). Hechos postdelictivos y sistema de individualización de la pena. Bilbao: Servicio Editorial de la Universidad del País Vasco, 2008, p. 125-144. 
LUHMANN, Niklas, Law as a Social System. Oxford: Oxford University Press, 2004.

LUNA, Erik. In Support of restorative justice. En: ROBINSON, Paul; GARVEY, Stephen; KESSLER, Kimberly (editores). Criminal law conversations. Oxford: Oxford University Press, 2009, p. 585-610.

MANNOZZI, Grazia. La giustizia senza spada. Uno studio comparato su giustizia riparativa e mediazione penale. Milano: Giuffré, 2003.

MAÑALICH, Juan Pablo. La pena como retribución. Segunda parte: La retribución como teoría el Derecho penal. Derecho Penal y Criminología, vol. 28, $\mathrm{n}^{\circ} 83$, 2007, p. 75-120.

MAÑALICH, Juan Pablo. Retribucionismo consecuencialista como programa de ideología punitiva. InDret, $\mathrm{n}^{\circ} 5,2015$, p. 1-32.

MAÑALICH, Juan Pablo. Retribucionismo expresivo. Acerca de la función comunicativa de la pena. En: KINDHÄUSER, Urs; MAÑALICH, Juan Pablo. Pena y culpabilidad en el Estado democrático de Derecho. Montevideo- Buenos Aires: B de F, 2011, p. 29-65.

MUÑOZ CONDE, Francisco; GARCÍA ARÁN, Mercedes. Derecho penal: parte general. 6ta edición. Valencia: Tirant lo Blanch, 2004.

NASH ROJAS, Claudio. Las Reparaciones ante la Corte Interamericana de Derechos Humanos (1988-2007). Segunda Edición. Santiago de Chile: Universidad de Chile, 2009.

PAWLIK, Michael. Ciudadanía y Derecho penal. Fundamentos de la teoría de la pena y del delito en un Estado de libertades. Trad. Ricardo Robles Planas y otros. Barcelona: Atelier, 2016.

PÉREZ BARBERÁ, Gabriel. Problemas y perspectivas de las teorías expresivas de la pena. InDret, $\mathrm{n}^{\circ} 4,2014$, p. 1-44.

PÉREZ SANZBERRO, Guadalupe. Reparación y conciliación en el sistema penal ¿Apertura de una nueva vía?. Granada: Comares, 1999.

RODRIGUEZ HORCAJO, Daniel. Comportamiento humano y pena estatal: disuasión, cooperación y equidad. Madrid- Barcelona- Buenos Aires- Sao Paulo: Marcial Pons, 2016.

SEELMANN, Kurt. Paradojas de la orientación hacia la víctima en el Derecho penal. En: SEELMANN, Kurt. Estudios de filosofía del Derecho y Derecho penal. Trad. Raúl Núñez Ojeda y Thomas Vogt Geisse. Madrid, Barcelona, Buenos Aires, São Paulo: Marcial Pons, 2013, p. 189-207. 
SILVA SÁNCHEZ, Jesús-María. Del Derecho abstracto al Derecho Real. Indret, $\mathrm{n}^{\mathrm{o}} 4,2016$, p. 1-6.

SILVA SÁNCHEZ, Jesús-María. En Busca del Derecho Penal. Esbozos de una teoría realista del delito y de la pena. Montevideo- Buenos Aires: B de F, 2015.

SILVA SANCHÉZ, Jesús-María. Malum Passionis. Mitigar el dolor del Derecho penal. Barcelona: Atelier, 2018.

STRATENWERTH, Günter. ¿Qué aporta la teoría de los fines de la pena?. Trad. Marcelo Sancinetti. Bogotá: Universidad Externado de Colombia, 1998.

TAMARIT SUMALLA, Josep M. Procesos restaurativos más allá de la mediación: perspectivas de futuro. En: AA.VV. Justicia restaurativa, una justicia para el siglo XXI: potencialidades y retos. Bilbao: Publicaciones Universidad de Deusto, 2013, p. $317-328$

TANGNEY, June P; STUEWIG, Jef; HAFEZ, Logaina. Shame, guilt, and remorse: implications for offender populations. The Journal of Forensic Psychiatry \& Psychology, vol. 22, no 5, p. 706-723, 2011. https://doi.org/10.1080/14789949.2011.617541

VAN CAMP, Tinneke, Understanding victim participation in restorative practices: Looking for justice for oneself as well as for others. European Journal of Criminology, vol. 14, nº, p. 679-696, 2016. https://doi.org/10.1177/1477370816682981

VAN NESS, Daniel W; HEETDERKS STRONG, Karen. Restoring justice: an introduction to restorative justice. 5ta edición. Ámsterdam- Boston- Heidelberg- London: Anderson Publishing, 2015.

VARONA GÓMEZ, Daniel, El debate ciudadano sobre la justicia penal y el castigo: razón y emoción en el camino hacia un derecho penal democrático. Madrid- Barcelona- Buenos Aires- São Paulo: Marcial Pons, 2016.

VENTUROLI, Marco. La vittima nel sistema penale dall'oblio al protagonismo?. Napoli: Jovene editore, 2015.

VON HIRSCH, Andrew; ASHWORTH, Andrew. Proportionate Sentencing: Exploring the Principles. Oxford: Oxford University Press, 2003.

VON HIRSCH, Andrew. Proportionality in the philosophy of punishment: from "why punish?" to "how much?. Israel Law Review, vol. 25, n 3-4, p. 549-580, 1991. https://doi.org/10.1017/s002122370001061x

VON HIRSCH, Andrew. Retribución y prevención como elementos de justificación de la pena. En: ARROYO ZAPATERO, Luis y otros (coordinadores). Crítica y 
justificación del Derecho penal en el cambio de siglo. Cuenca: Ediciones Universidad de Castilla-La Mancha, 2003, p. 125-145.

VON HIRSCH, Andrew. Censure and sanctions. Oxford- New York: Oxford University Press, 2003.

WEIGEND, Thomas. Tagungsbericht (Diskussionsbeiträge der Strafrechtslehrertagung 1981 in Bielefeld). Zeitschrift für die gesamte Strafrechtswissenschaft [ZstW], no 93, 1981, p. 1271-1290.

WEMMERS, Jo-anne; CYR, Katie. Victims' perspectives on restorative justice: how much involvement are victims looking for?. International Review of Victimology, vol. 3, p. 259-274, 2004. https://doi.org/10.1177/026975800401100204

WEMMERS, Jo-Anne. Victims' experiences in the criminal justice system and their recovery from crime. International Review of Victimology, vol 19, $\mathrm{n}^{\circ} 3, \mathrm{p}$. 221-233, 2013. https://doi.org/10.1177/0269758013492755

WRIGHT, Martin. Justice for victims and offenders a restorative response to crime. 2da edición. Winchester: Waterside Press, 1996.

\section{Informações adicionais e declarações dos autores (integridade científica)}

Declaração de conflito de interesses (conflict of interest declaration): o autor confirma que não há conflitos de interesse na realização das pesquisas expostas e na redação deste artigo.

Declaração de autoria e especificação das contribuições (declaration of authorship): todas e somente as pessoas que atendem os requisitos de autoria deste artigo estão listadas como autores; todos os coautores se responsabilizam integralmente por este trabalho em sua totalidade.

Declaração de ineditismo e originalidade (declaration of originality): o autor assegura que o texto aqui publicado não foi divulgado anteriormente em outro meio e que futura republicação somente se realizará com a indicação expressa da referência desta publicação original; também atesta que não há plágio de terceiros ou autoplágio. 
Dados do processo editorial

(http://www.ibraspp.com.br/revista/index.php/RBDPP/about/editorialPolicies)

- Recebido em: 31/12/2018

- Controle preliminar e verificação de plágio: 08/01/2019

- Avaliação 1: 11/01/2019

- Avaliação 2: 20/01/2019

- Avaliação 3: 23/01/2019

- Avaliação 4: 24/01/2019

- Decisão editorial preliminar: 26/01/2019

- Retorno rodada de correções: 10/02/2019

- Decisão editorial final: 10/02/2019
Equipe editorial envolvida

- Editor-chefe: 1 (VGV)

- Editor-associado: 1 (ELL)

- Revisores: 4

\section{COMO CITAR ESTE ARTIGO:}

BELTRÁN CALFURRAPA, Ramón. Víctima, reparación y proceso penal: una proyección desde las teorías expresivas de la pena. Revista Brasileira de

Direito Processual Penal, Porto Alegre, vol. 5, n. 1, p. 145-190, jan./abr. 2019.

https://doi.org/10.22197/rbdpp.v5i1.215

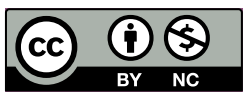

Esta obra está licenciada com uma Licença Creative Commons Atribuição-NãoComercial 4.0 Internacional. 